\title{
Effect of oat supplementation interventions on cardiovascular disease risk markers: a systematic review and meta-analysis of randomized controlled trials
}

\author{
Erand Llanaj ${ }^{1,2} \cdot$ Gordana M. Dejanovic $^{3} \cdot$ Ezra Valido $^{4} \cdot$ Arjola Bano $^{9,14} \cdot$ Magda Gamba $^{9,13} \cdot$ Lum Kastrati $^{10}$. \\ Beatrice Minder ${ }^{11}$. Stevan Stojic ${ }^{4} \cdot$ Trudy Voortman $^{5,6} \cdot$ Pedro Marques-Vidal $^{7,8}$. Jivko Stoyanov ${ }^{4,9}$. \\ Brandon Metzger ${ }^{12} \cdot$ Marija Glisic $^{4,9} \cdot$ Hua Kern ${ }^{12} \cdot$ Taulant Muka $^{9}$
}

Received: 1 July 2021 / Accepted: 30 November 2021 / Published online: 3 January 2022

(C) The Author(s) 2021

\begin{abstract}
Purpose Oat supplementation interventions (OSIs) may have a beneficial effect on cardiovascular disease (CVD) risk. However, dietary background can modulate such effect. This systematic review assesses the effects of OSIs on CVD risk markers among adults, accounting for different dietary backgrounds or control arms.

Methods We included randomized clinical trials (RCTs) that assessed the effect of oat, oat beta-glucan-rich extracts or avenanthramides on CVD risk markers.

Results Seventy-four RCTs, including 4937 predominantly hypercholesterolemic, obese subjects, with mild metabolic disturbances, were included in the systematic review. Of these, 59 RCTs contributed to the meta-analyses. Subjects receiving an OSI, compared to control arms without oats, had improved levels of total cholesterol (TC) [weighted mean difference and $(95 \% \mathrm{CI})-0.42 \mathrm{mmol} / \mathrm{L},(-0.61 ;-0.22)], \mathrm{LDL}$ cholesterol $[-0.29 \mathrm{mmol} / \mathrm{L},(-0.37 ;-0.20)]$, glucose $[-0.25 \mathrm{nmol} / \mathrm{L}$, $(-0.36 ;-0.14)]$, body mass index $\left[-0.13 \mathrm{~kg} / \mathrm{m}^{2},(-0.26 ;-0.01)\right]$, weight $[-0.94 \mathrm{~kg},(-1.84:-0.05)]$, and waist circumference $[-1.06 \mathrm{~cm},(-1.85 ;-0.27)]$. RCTs on inflammation and/or oxidative stress markers were scarce and with inconsistent findings. RCTs comparing an OSI to heterogeneous interventions (e.g., wheat, eggs, rice, etc.), showed lowered levels of glycated haemoglobin, diastolic blood pressure, HDL cholesterol and apolipoprotein B. The majority of included RCTs $(81.1 \%)$ had some concerns for risk of bias.

Conclusion Dietary OSIs resulted in lowered levels of blood lipids and improvements in anthropometric parameters among participants with predominantly mild metabolic disturbances, regardless of dietary background or control. Further highquality trials are warranted to establish the role of OSIs on blood pressure, glucose homeostasis and inflammation markers.
\end{abstract}

Keywords Oats $\cdot$ Supplementation $\cdot$ Interventions $\cdot$ Cardiovascular diseases $\cdot$ Risk markers $\cdot$ Cholesterol $\cdot$ Nutrition

Erand Llanaj and Gordana M. Dejanovic have contributed equally to this work.

Hua Kern and Taulant Muka are last authors to all academic and professional effects, and that their names can be legitimately swapped in their respective publication list.

Taulant Muka

taulant.muka@ispm.unibe.ch

Extended author information available on the last page of the article

\section{Introduction}

Cardiovascular diseases (CVDs) represent one of the leading causes of global mortality among adults and lifestyle modifications have emerged as a great opportunity to reduce their health burden [1]. Hence, changes in diet have been encouraged, as they can have a beneficial impact on the prevention, management and disease trajectory of CVDs [2]. Among currently implemented dietary interventions, increased intake of whole grains and in particular oat components, such as oat fibre and oat bioactive constituents, has been suggested to affect CVD risk markers including blood cholesterol, blood glucose and body mass index (BMI), thus reducing the risk of coronary heart disease 
[3-6]. There is growing evidence suggesting that oat products, when compared with similar wheat-based products or a glucose control, can have a positive effect on human glycaemic response [7]. Similar positive effects have been also reported for overall CVD risk [8], satiety [9] and increased gut microbiota diversity [10]. Currently, a considerable number of randomized controlled trials (RCTs) and reviews have documented the health benefits that oat supplementation interventions (OSIs) confer, but such efforts are limited to a basic subset of CVD risk markers [6, 11]. In addition, little attention has been given to the role of background diet and control arm in the interpretation of the relationship between OSIs and CVD markers. Differentiating such effects [12, 13] by type of dietary OSI and/or control arm (e.g., oat-free intervention, low-fat diet, wheat, rice, etc.) can aid in harnessing the potential benefits of small, but consistent dietary changes, such as supplementing one's diet with oats. With that in mind, we aimed at examining the effect of OSIs on a more extended set of CVD risk markers, while also taking into consideration dietary backgrounds and type of control arms used in the RCTs that explored how OSIs affected CVD risk markers. Following this rationale and based on the available RCTs, three major sub-classes emerged as follows: (i) RCTs comparing an OSI vs. oat-free diet or control product without oats, (ii) intervention group combining an OSI with some type of dietary restriction (e.g., low-fat diet, hypocaloric diet, etc.) vs. the same dietary restriction alone and (iii) an OSI vs. heterogeneous control arms (e.g., rice, eggs, fibre, wheat, etc.). Based on this categorization, we assessed the association of OSIs and CVD risk markers in adults, accounting for each subclass.

\section{Materials and methods}

\section{Search strategy and study selection}

This work follows an established guide on conducting systematic reviews and meta-analyses for medical research [14], as well as PRISMA [15] guidelines for reporting. An experienced medical librarian systematically searched four electronic databases: EMBASE, MEDLINE (Ovid), Cochrane Central and Web of Science from inception until May 15, 2020 (date last searched); additionally, the first 200 results were downloaded from the Google Scholar search engine. A detailed search strategy is outlined in the supplementary material (section Search strategy). We additionally performed a hand search of the reference lists of included RCTs. Detailed inclusion and exclusion criteria can be found in the review protocol PROSPERO (ID: CRD42020189278). In brief, RCTs were included only if they (i) were conducted in humans and (ii) investigated the associations of oat, oat beta-glucan-rich extracts (OßGREs) and/or avenanthramides dietary supplementation with any of the following outcomes: serum lipid profile, glucose homeostasis parameters, inflammatory and oxidative stress markers, body morphology parameters and/or blood pressure.

\section{Data extraction and assessment of the quality of included studies}

Two reviewers, who afterwards assessed the full-texts of potentially eligible studies, independently evaluated titles and abstracts. Two reviewers also independently extracted the relevant information using a pre-defined data extraction form. Any disagreement between reviewers was settled by reaching a consensus or by consulting a third reviewer. The quality of included RCTs was assessed by two independent reviewers using the Risk of Bias Tool for Randomized Trials (Rob 2.0) [16]. Detailed information on the assessment of study quality and risk of bias is provided in Table 1.

\section{Statistical analysis}

Treatment effects were defined as the pre-post differences in outcomes between OSIs and control arms at the end of a RCT. All outcomes were continuous, therefore, the mean differences [intervention minus control] of the treatment effects in CVD risk markers were presented as summary outcome measures. For data reported as medians, ranges or $95 \%$ confidence intervals (CI), means and standard deviations were converted as described elsewhere [17]. Random-effect models were used to obtain estimates of weighted mean differences (WMDs) and 95\%CIs. For RCTs with crossover design, we used the data from the first study period only. Due to observed variations between the definition of intervention and control diet across different RCTs, we pooled the effect estimates by grouping the following type of RCTs based on background diet and control arm: (i) an OSI group compared with the same/other intervention groups, but without oats (ii) intervention group combining an OSI and some type of dietary restriction (DR) (e.g., low-fat diet, hypocaloric diet, etc.) versus the same DR without oats, and (iii) an OSI compared with other interventions (e.g. rice, eggs, fibre, wheat, etc.). Henceforth these groups will be referred to their short form as (i) OSI vs. no OSI controls, (ii) OSI+DR vs. DR alone and (iii) OSI vs. heterogeneous controls, respectively. Heterogeneity between studies was assessed using the Cochrane $\chi^{2}$ statistic $\left(\mathrm{P}_{\mathrm{q}}<0.05\right.$ was considered as significant) and the $I^{2}$ statistic, and was determined as low $\left(I^{2} \leq 25 \%\right)$, moderate $\left(25 \%<I^{2}<75 \%\right)$, or high $\left(I^{2} \geq 75 \%\right)$ [18]. Study characteristics including geographic location, number of participants, duration of intervention, baseline age, health status (healthy individuals vs. those with pre-existing health conditions), and study quality were pre-specified as characteristics for assessment of heterogeneity, and were evaluated using stratified analyses and 


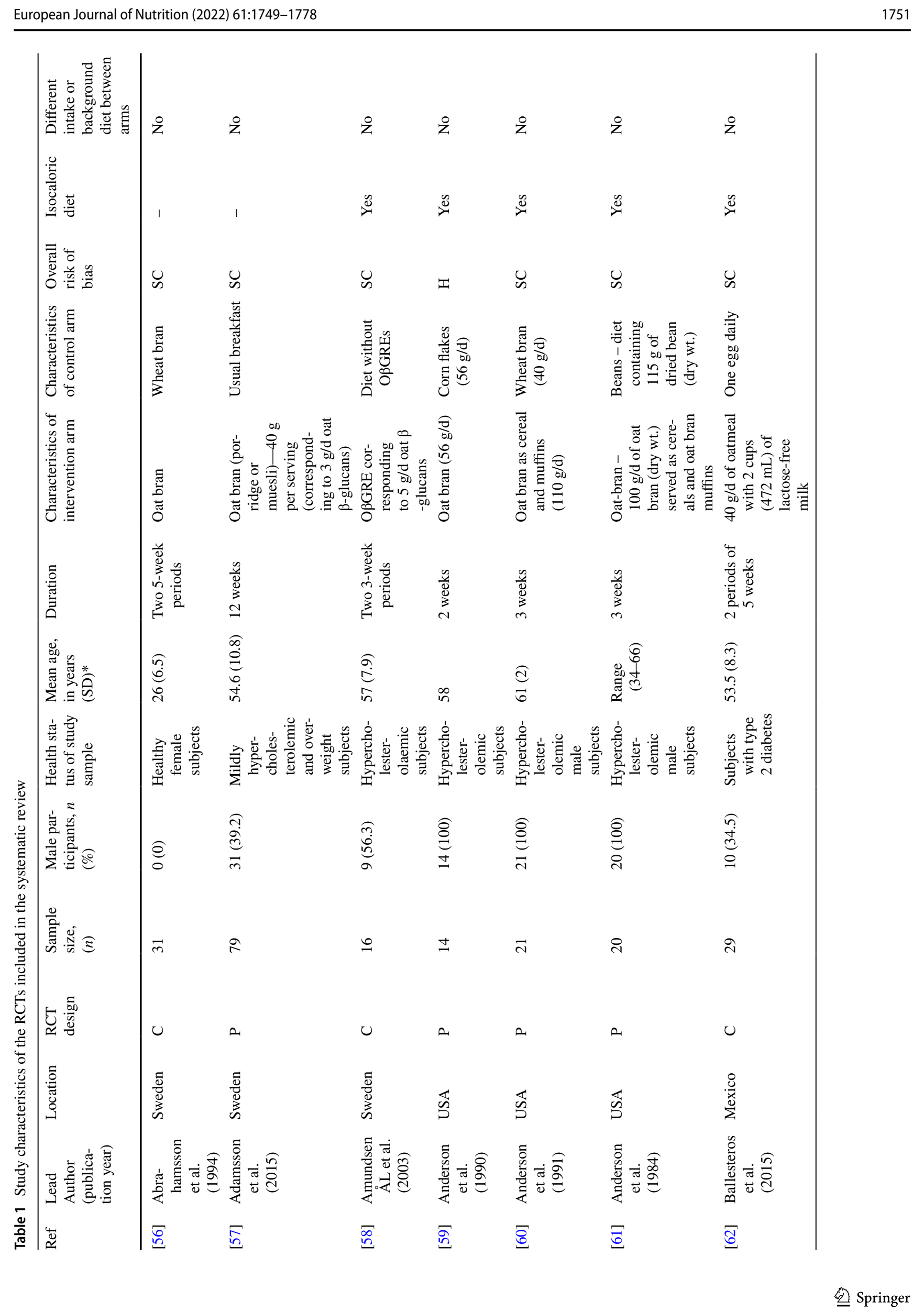




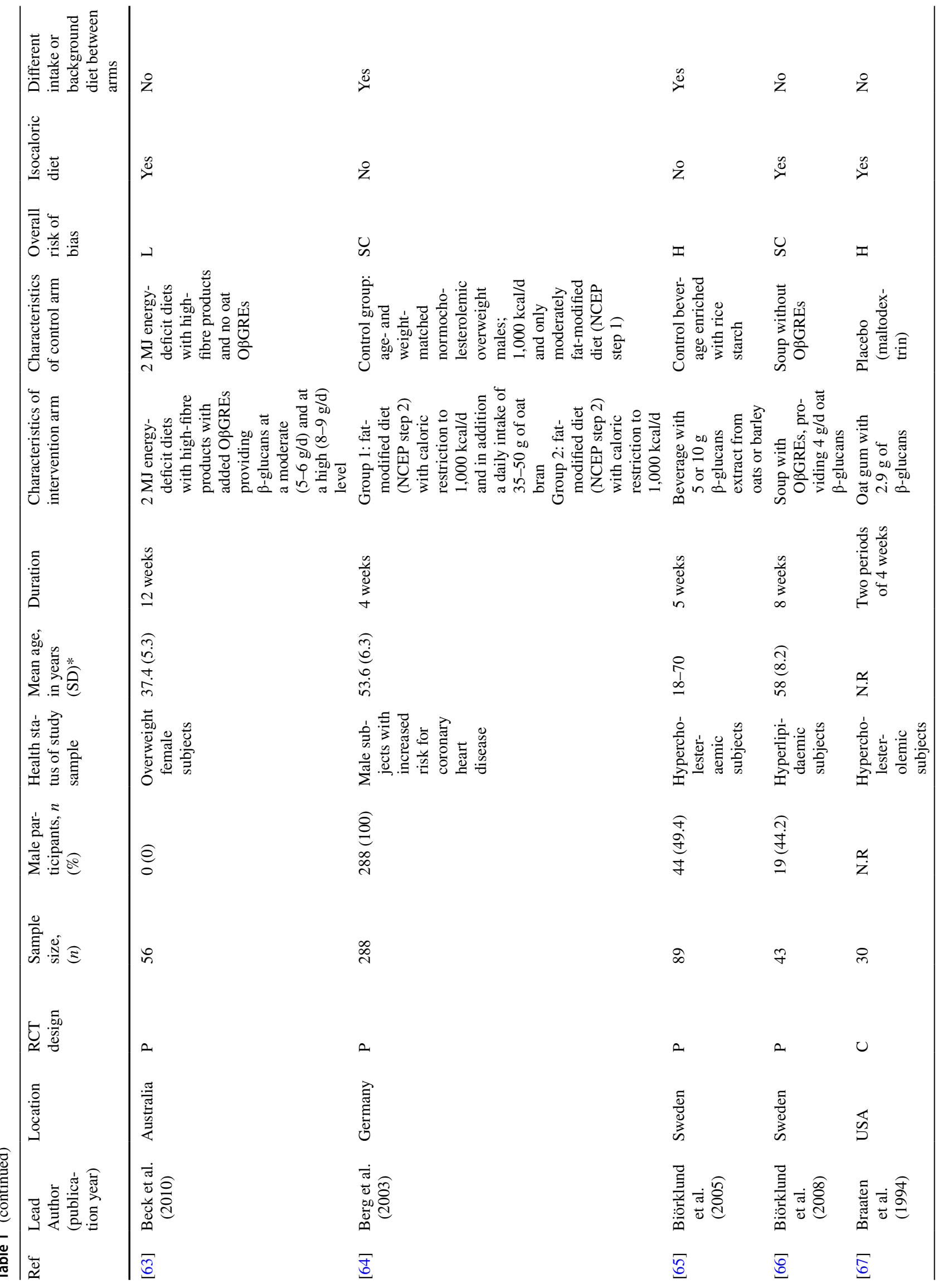




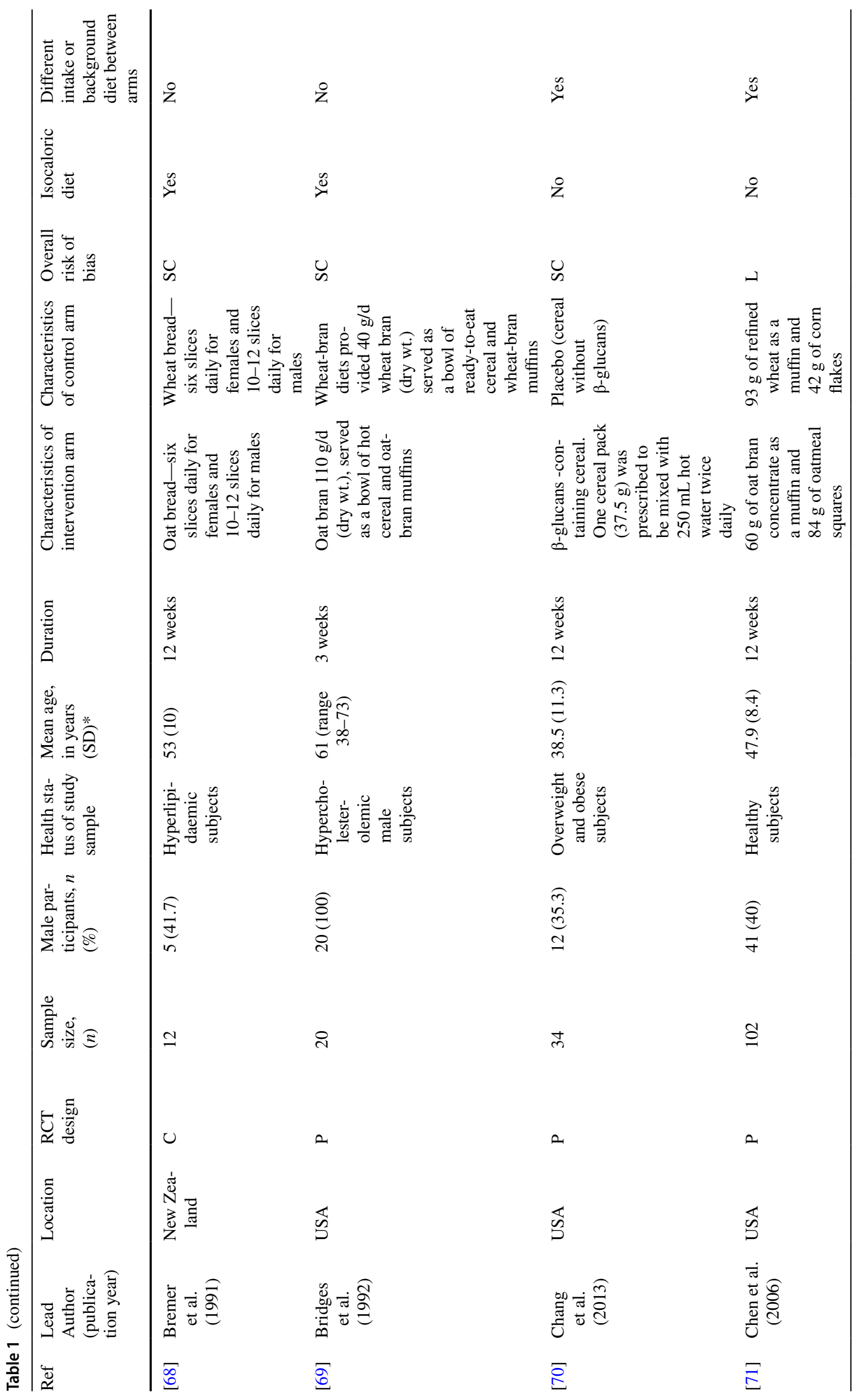




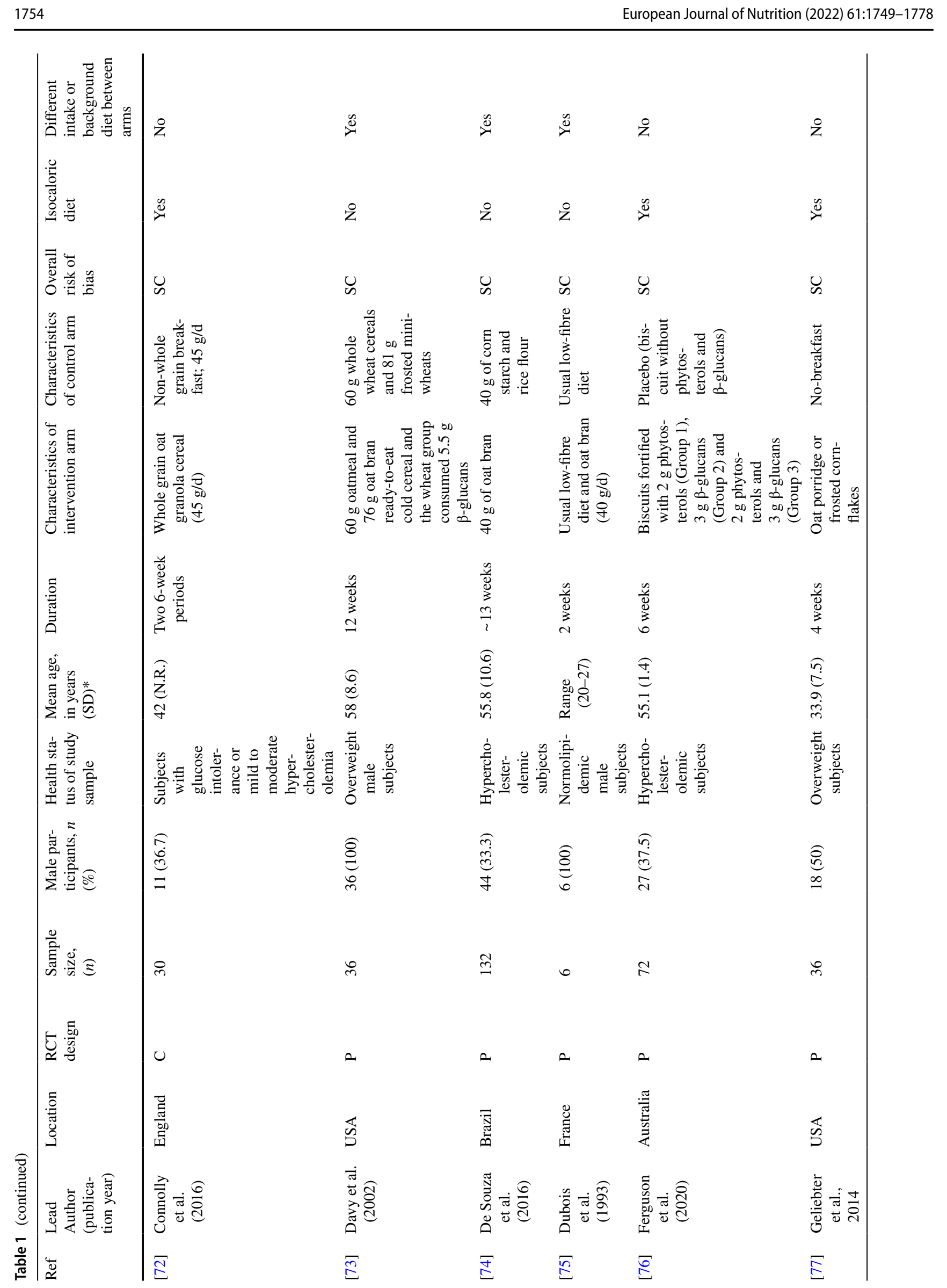

Springer 


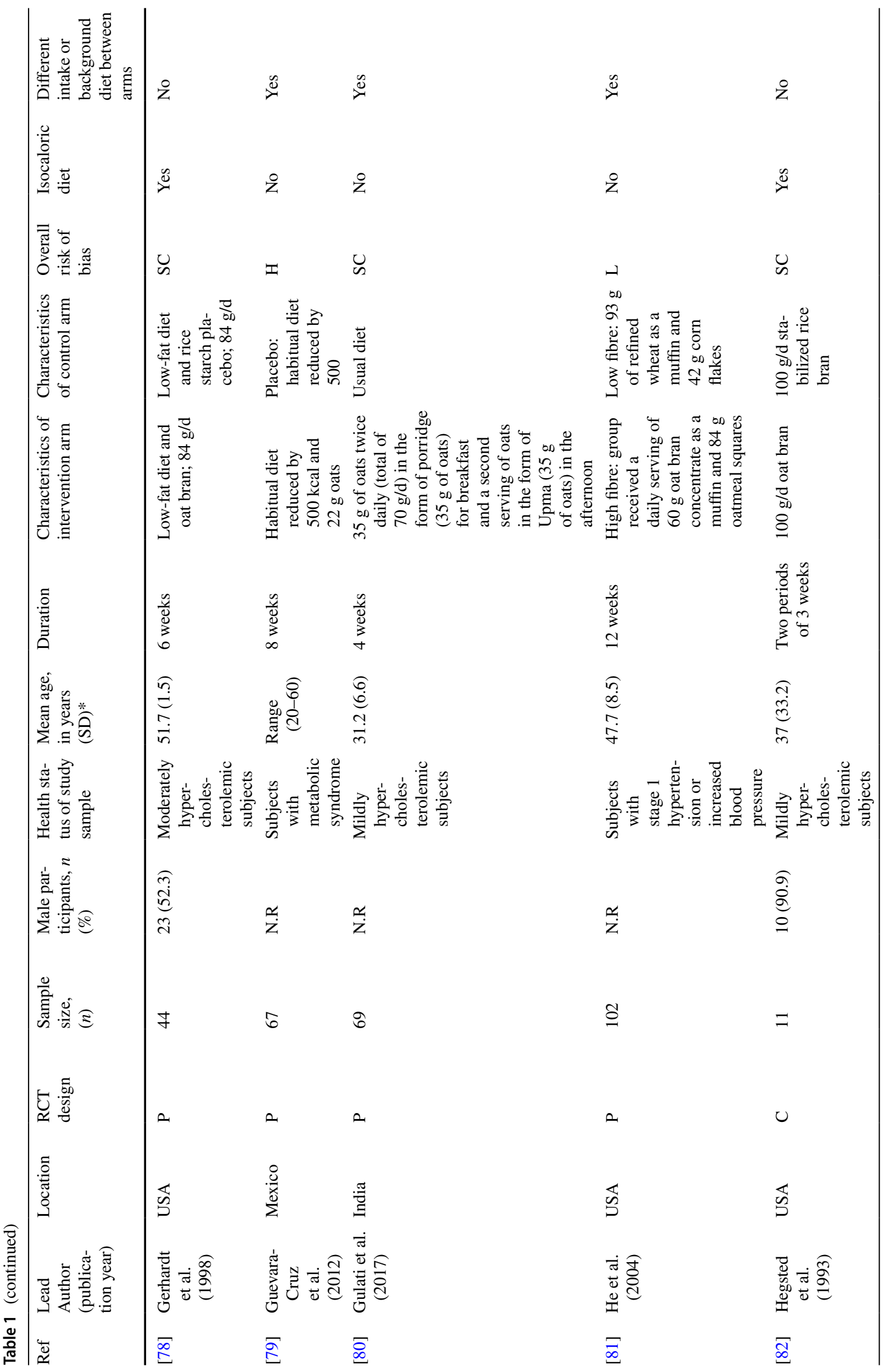




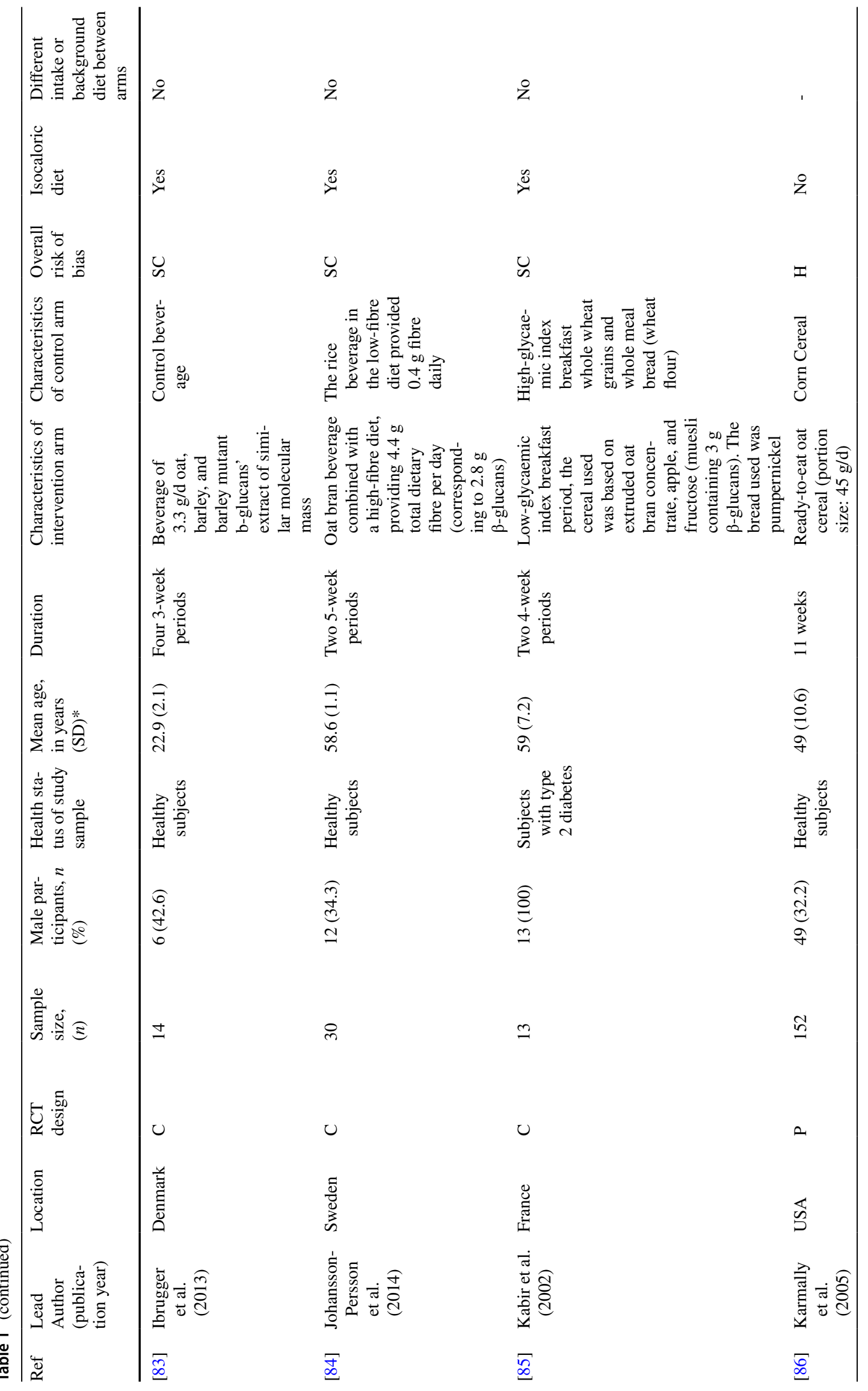




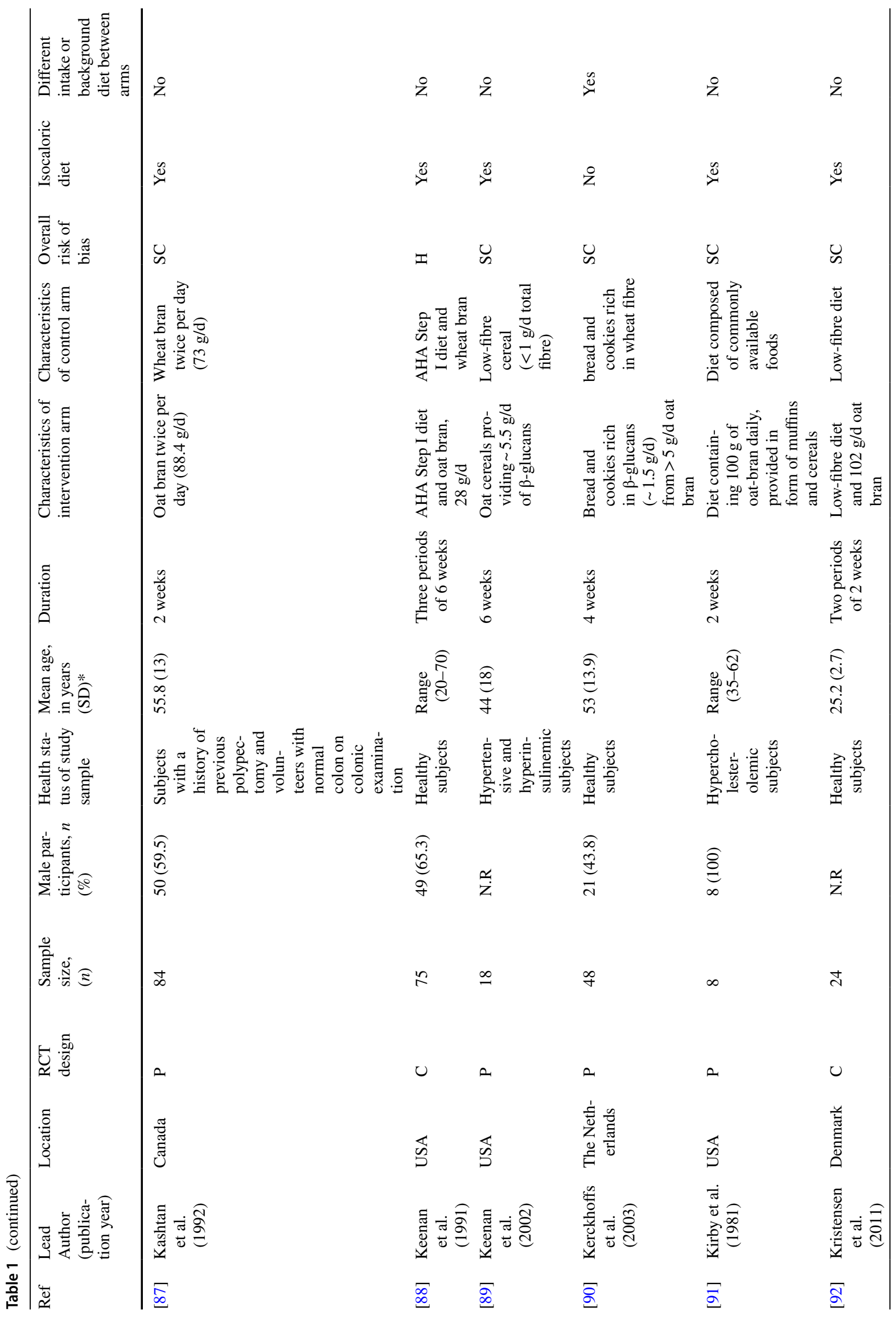




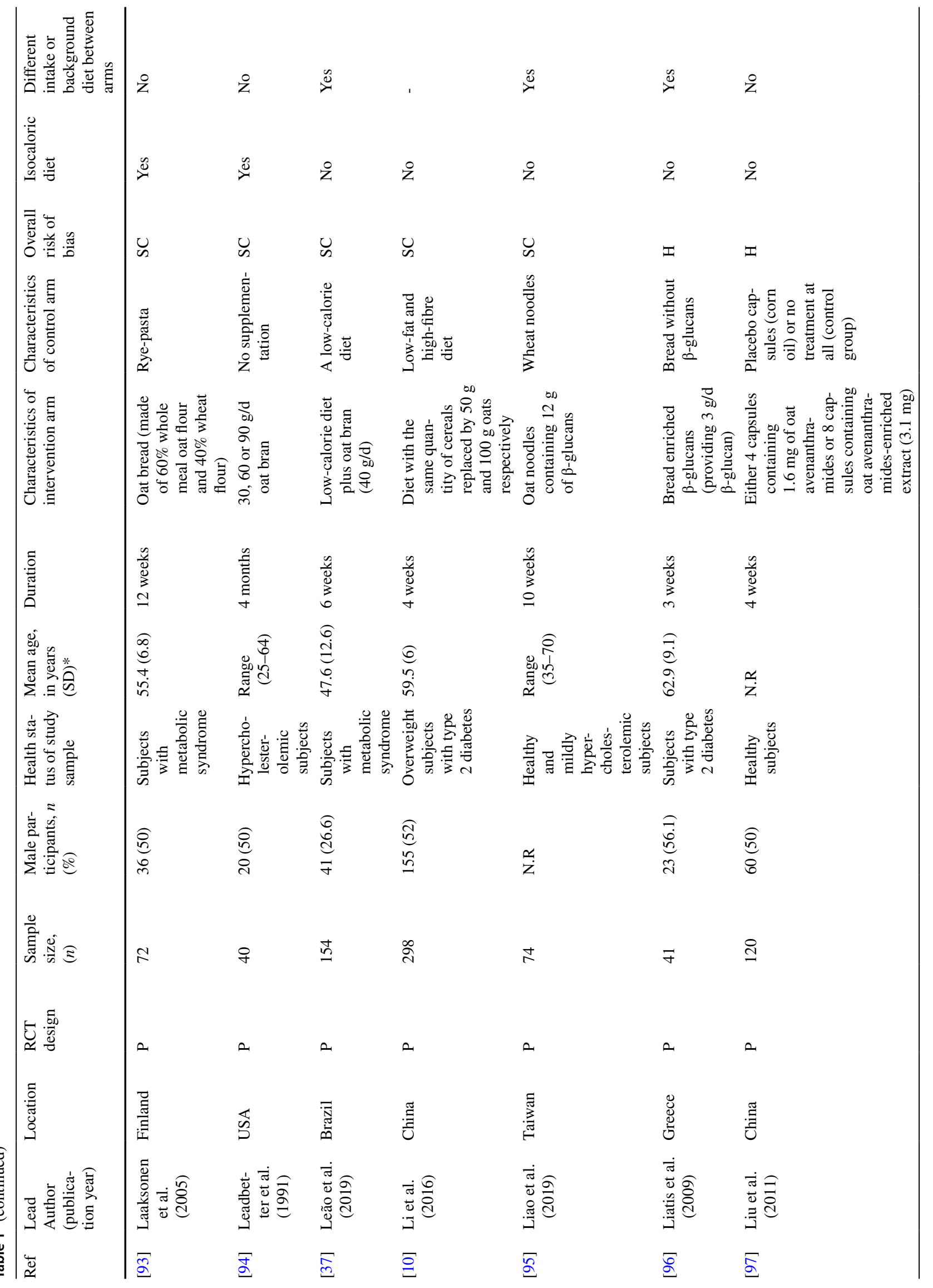




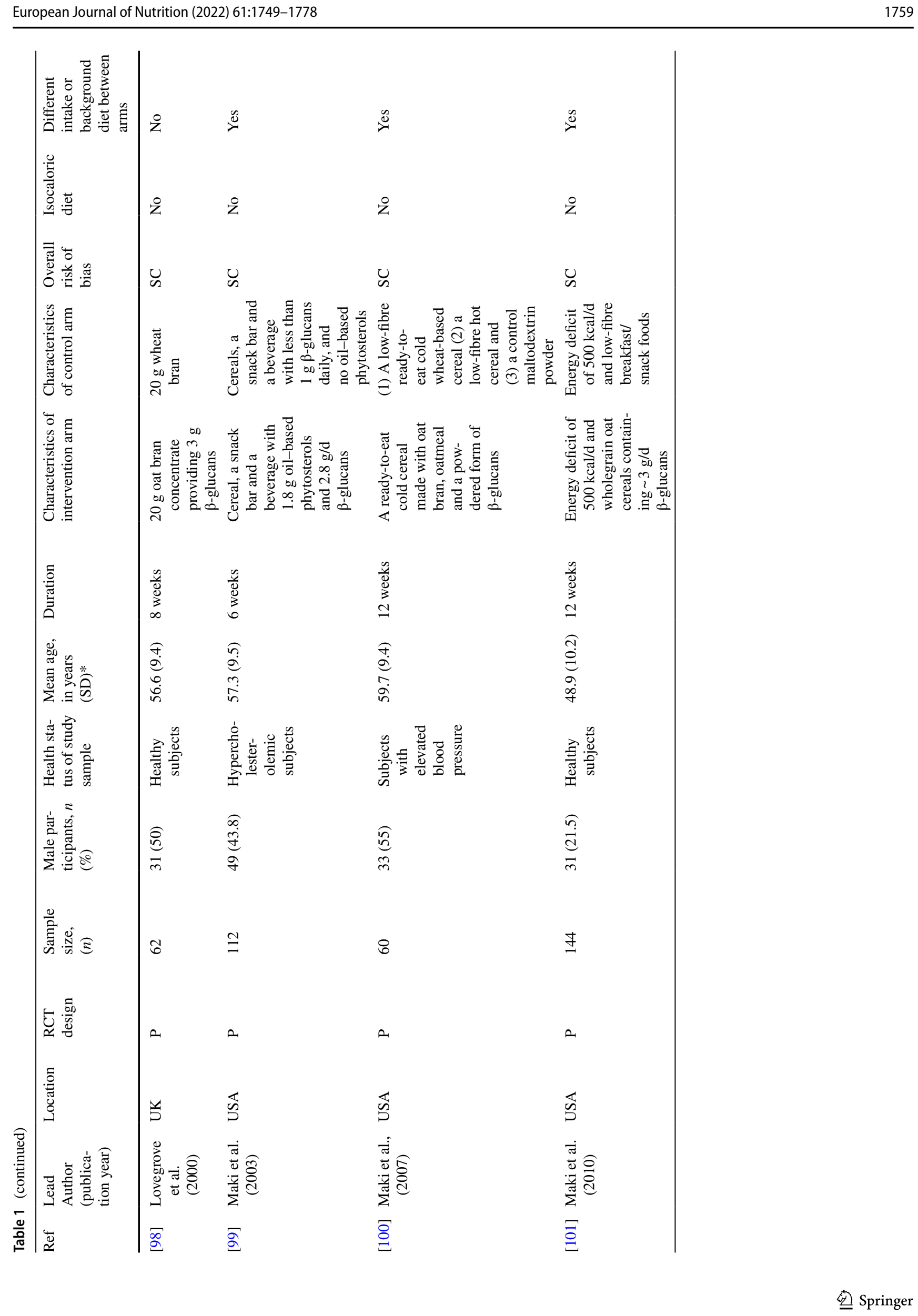




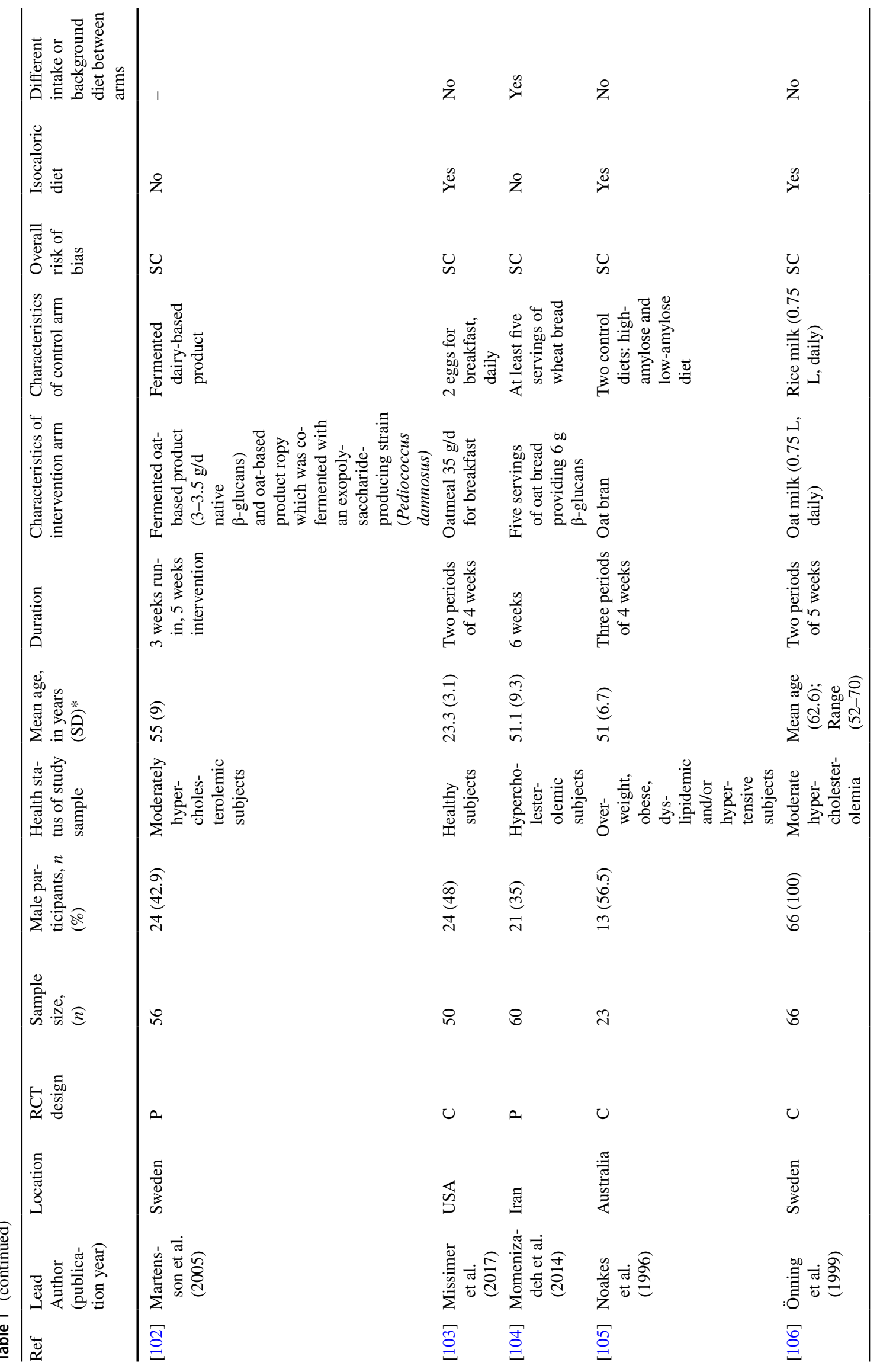




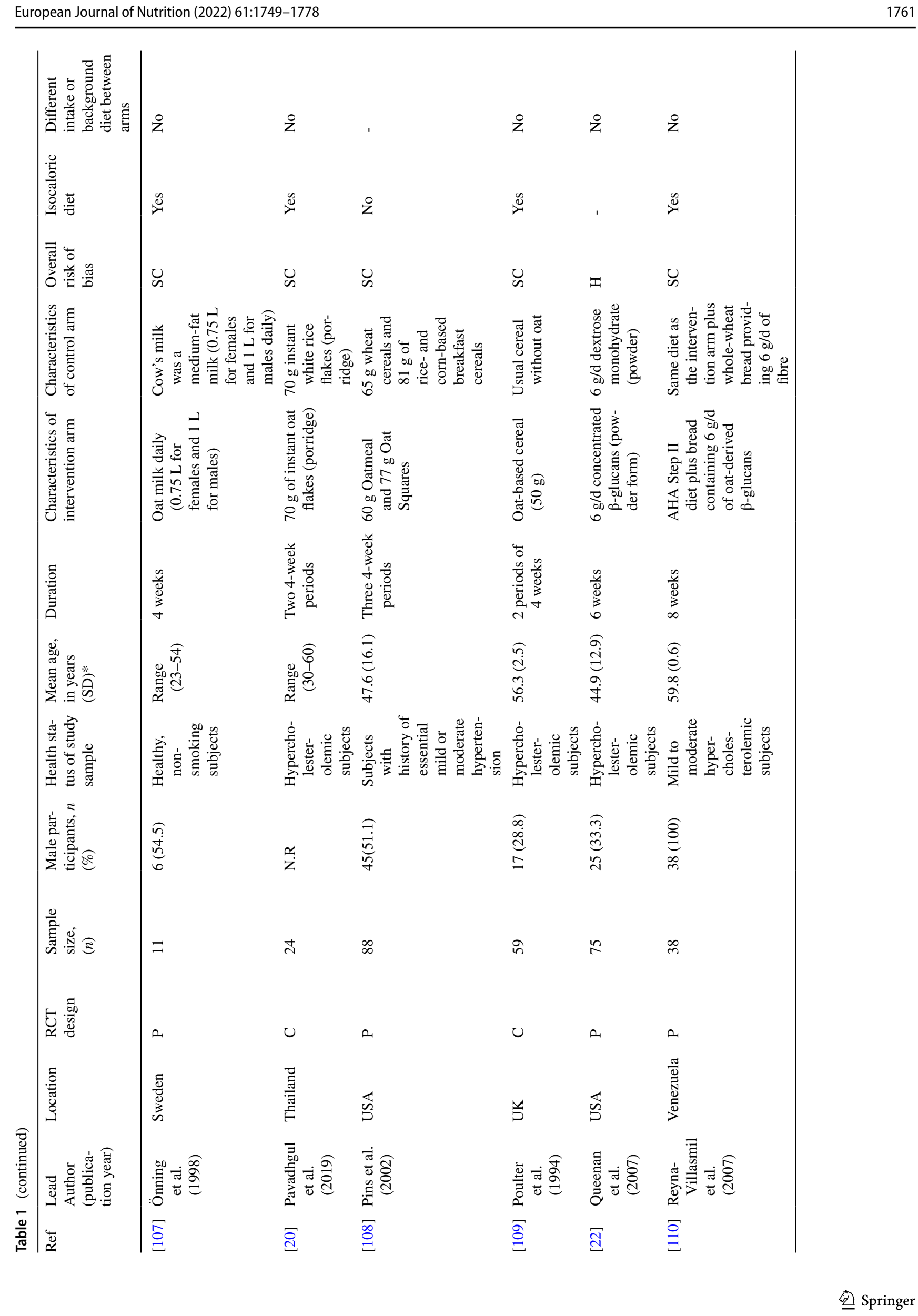




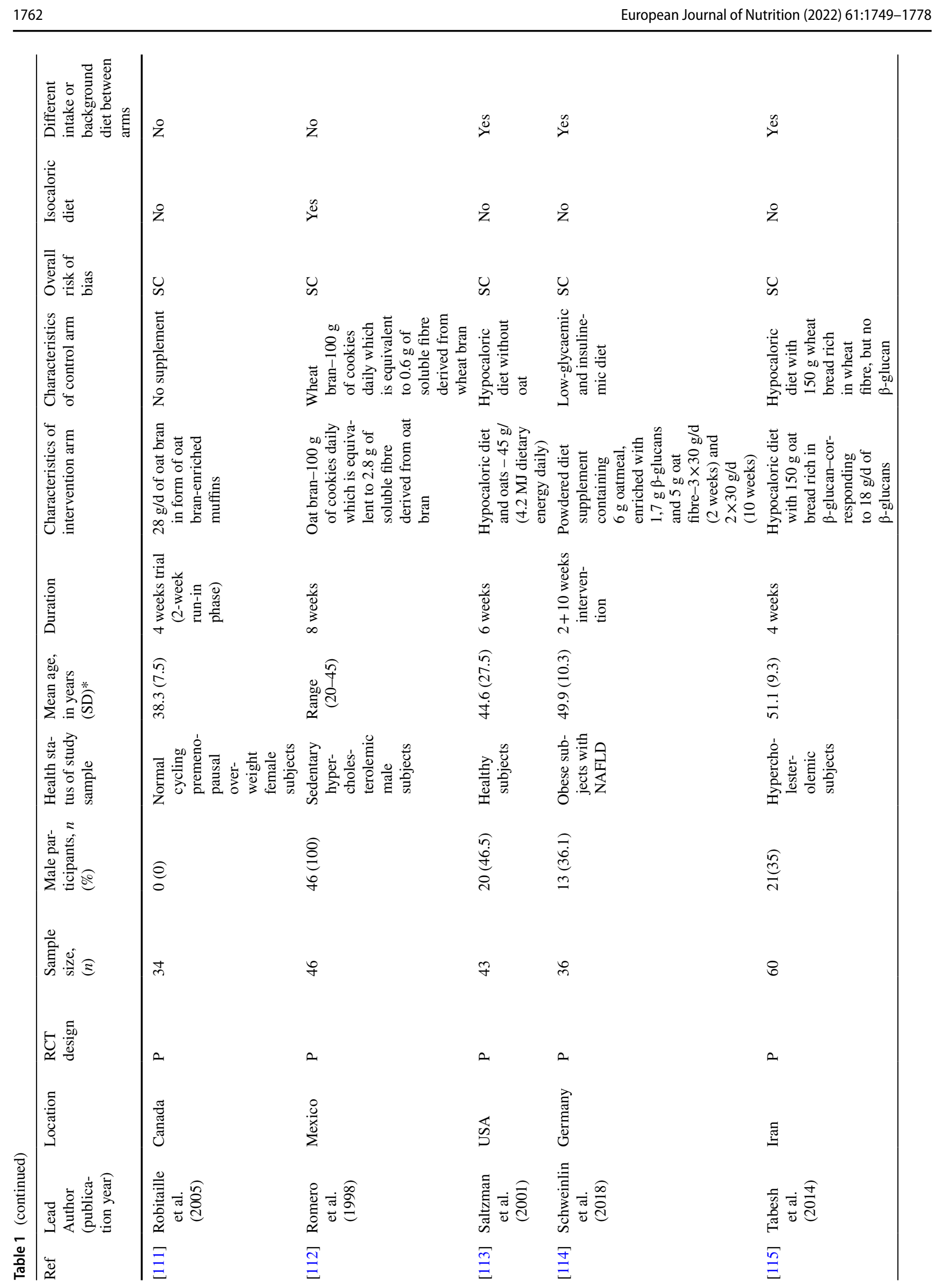

Springer 


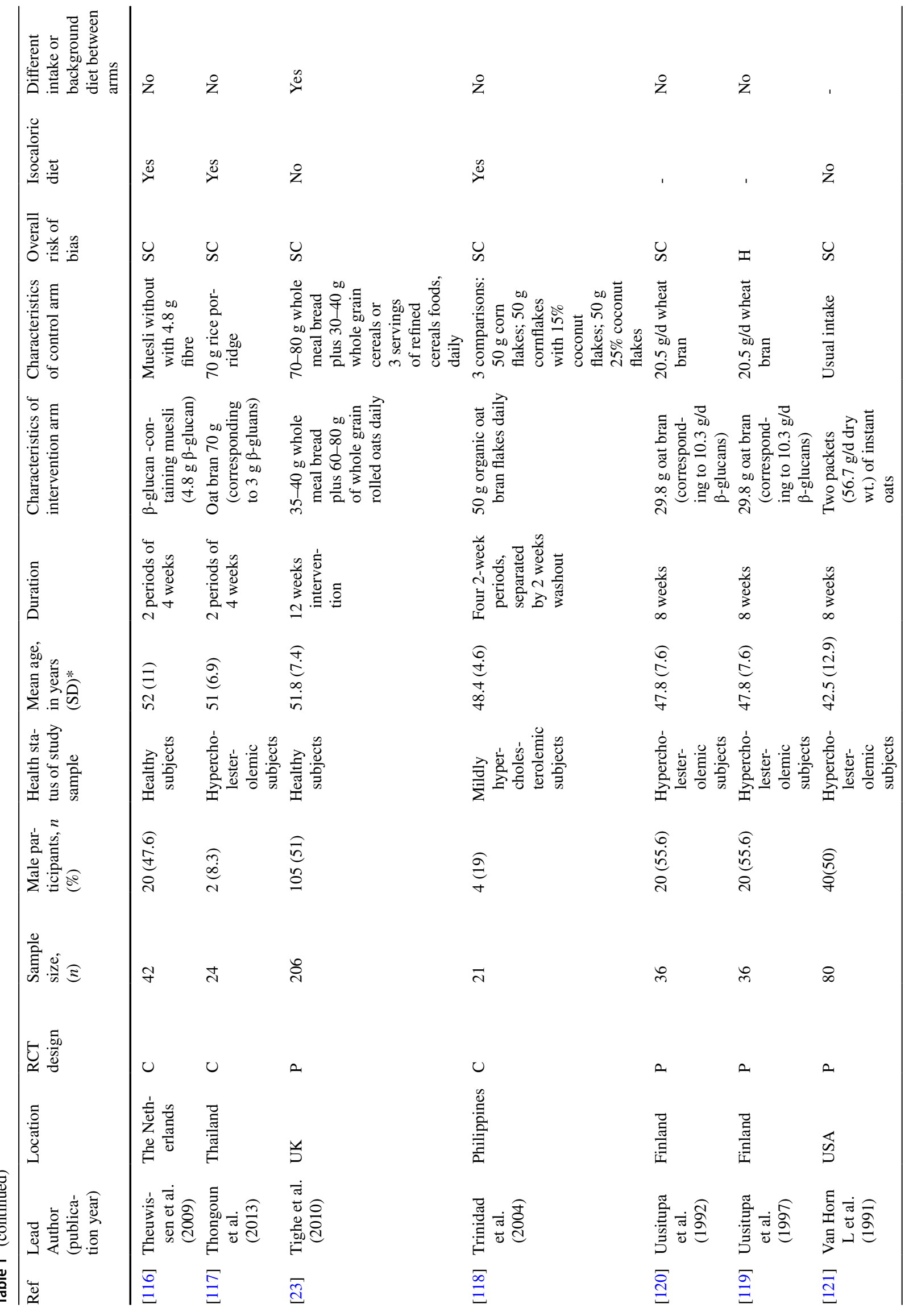


1764

European Journal of Nutrition (2022) 61:1749-1778

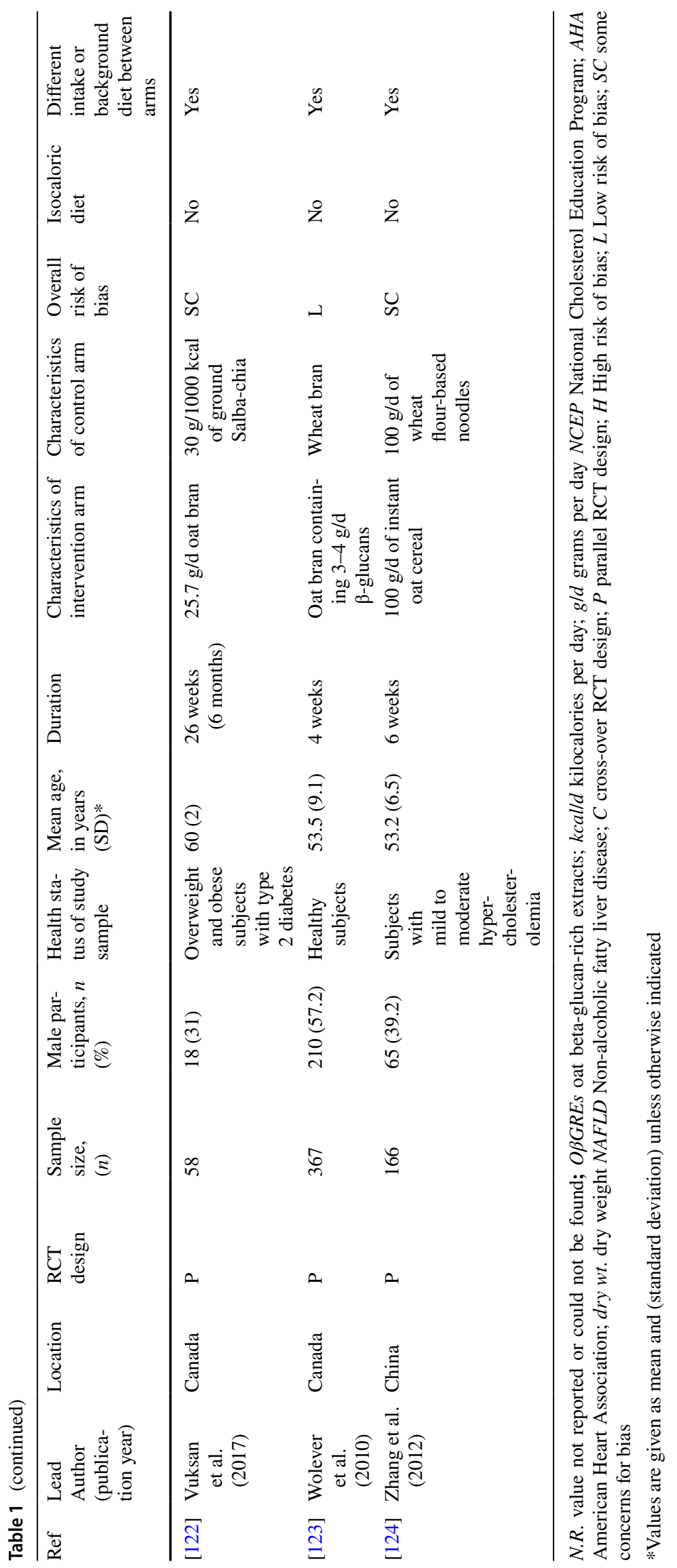

Springer 
random-effects meta-regression, if eight or more studies were included in the meta-analysis [19]. We performed a leaveone-out sensitivity analysis iteratively by removing one study at a time to explore whether any single study influenced the results. Publication bias was evaluated through visual inspection of funnel plot and Egger's test. All statistical analyses were conducted with STATA, Release 16 (Stata Corp, College Station, Texas, USA). The RCTs that could not be quantitatively pooled were qualitatively summarized.

\section{Results}

\section{Included studies}

Of 3239 unique citations yielded from the search strategy, 116 relevant full-text articles were retrieved, of which 57 RCTs met all eligibility criteria. We screened the reference lists of those 57 RCTs and identified an additional 17 studies that met all criteria. As a result, a total of 74 RCTs were included in the systematic review, comprising 4,937 individuals. Among the 74 included RCTs, only 59 could be included in the metaanalysis (Fig. 1). Twenty-nine RCTs were conducted in North America, twenty-five in Europe, thirteen in Asia-Pacific and seven in South America. The sample size ranged from 6 to 298 individuals (median 45, interquartile range (IQR): 36-60) and the duration of the interventions from 2 to 26 weeks (median 8 weeks, IQR: $4.25-12)$. The majority of RCTs $(n=56,75.7 \%)$ included individuals with some form of metabolic disturbance (i.e., type 2 diabetes (T2D), metabolic syndrome, prediabetes, prehypertension, hyperlipidaemia), while only 18 RCTs were conducted in healthy individuals. The majority of the RCTs $(n=60,81.1 \%)$ investigated oat bran, meal or porridge supplementation, 13 RCTs reported on $\beta$-glucan- containing oat products and one investigated avenanthramides (Table 1). Only 35 (47.3\%) out of 74 RCTs took energy intake into account between trial arms. The majority of studies (60 out of 74 , $81.1 \%$ ) were evaluated as having some concerns about risk of bias, mostly due to issues linked to randomization, allocation and blinding. Ten studies (13.5\%) had high risk of bias and four studies (5.4\%) had low risk of bias (see Tables 1 and 2). Among the 59 RCTs included in the meta-analysis, 12 contributed to the main meta-analysis (comparing OSI vs. no OSI controls), 12 contributed to the meta-analysis comparing an OSI + DR vs. DR alone, and 35 contributed to the metaanalysis comparing an OSI vs. heterogeneous control arms.

\section{Meta-analysis of RCTs comparing oat supplementation interventions with the same intervention without oat product}

Twelve RCTs contributed to the main meta-analysis comparing the effects of an OSI vs. no OSI controls, on CVD risk markers. In this comparison, the OSI was associated with a higher decrease in total cholesterol (TC) $[\mathrm{WMD}$ and $(95 \% \mathrm{CI})-0.42 \mathrm{mmol} / \mathrm{L},(-0.61$; $\left.-0.22), I^{2}=96.1 \%, P_{\mathrm{q}}<0.001\right]$ and low-density lipoprotein cholesterol (LDL-C) $[-0.29 \mathrm{mmol} / \mathrm{L},(-0.37$; $\left.-0.20), I^{2}=72.6 \%, P_{\mathrm{q}}<0.001\right]$ (Table 2 ). In addition, glucose $\left[-0.25 \mathrm{mmol} / \mathrm{L},(-0.36 ;-0.14), I^{2}=47.9 \%\right.$, $\left.P_{\mathrm{q}}=0.15\right]$, BMI $\left[-0.33 \mathrm{~kg} / \mathrm{m}^{2},(-0.63 ;-0.03)\right.$, $\left.I^{2}=55.6 \%, P_{\mathrm{q}}=0.09\right]$, body weight $[-0.94 \mathrm{~kg},(-1.84$ : - 0.05) $\left.I^{2}=52.3 \%, P_{\mathrm{q}}=0.09\right]$ and waist circumference (WC) $\left[-1.06 \mathrm{~cm},(-1.85 ;-0.27), I^{2}=0 \%, P_{\mathrm{q}}=0.61\right]$ were lower in the OSI group compared to the control arm (Table 2). We found no differences in high-density lipoprotein cholesterol (HDL-C), triglycerides (TGs), or blood pressure (BP) when comparing the OSI arm to that of no OSI controls (Table 2).

\section{Subgroup analysis, leave-one-out analysis and publication bias}

Subgroup analyses, meta-regression and analysis of sources of heterogeneity were conducted only if at least 8 studies were available. We identified high heterogeneity across different studies ( $I^{2}$ ranged from 0 to $96.1 \%$ ). Due to the limited number of studies included in our analyses, we were able to explore sources of heterogeneity only in the meta-analysis of blood lipids (subgroup analyses were not performed if less than 8 studies contributed to metaanalyses). Besides the percentage of male study participants, which was identified as potential source of heterogeneity in case of LDL-C, the heterogeneity in the other meta-analyses of blood lipids was not explained by any individual participant nor study characteristics (e.g., age, health status, number of participants, duration of intervention and location) (Supplemental Table 2). The findings were also supported by regressing continuous variables, such as age, duration of study and number of study participants-showing no evidence for linear association between those variables and WMD of TC, HDL-C, LDL-C and TGs (Supplemental Figs. 8-11). Due to the limited number of studies included, we could not stratify the metaanalyses based on intervention type (oat or OßGREs) or on intervention's daily dose. The leave-one-out analyses did not show any study to influence the results on TC, HDL-C, LDL-C and TGs (Supplemental Tables 3-6); the leaveone-out analysis was not feasible for other outcomes due to the limited number of studies. We found no evidence for publication bias of RCTs included in meta-analysis comprising five or more estimates; funnel plots were in general symmetrical and Egger's $p$ values were higher than 0.05 (Supplemental Figs. 9-16). 


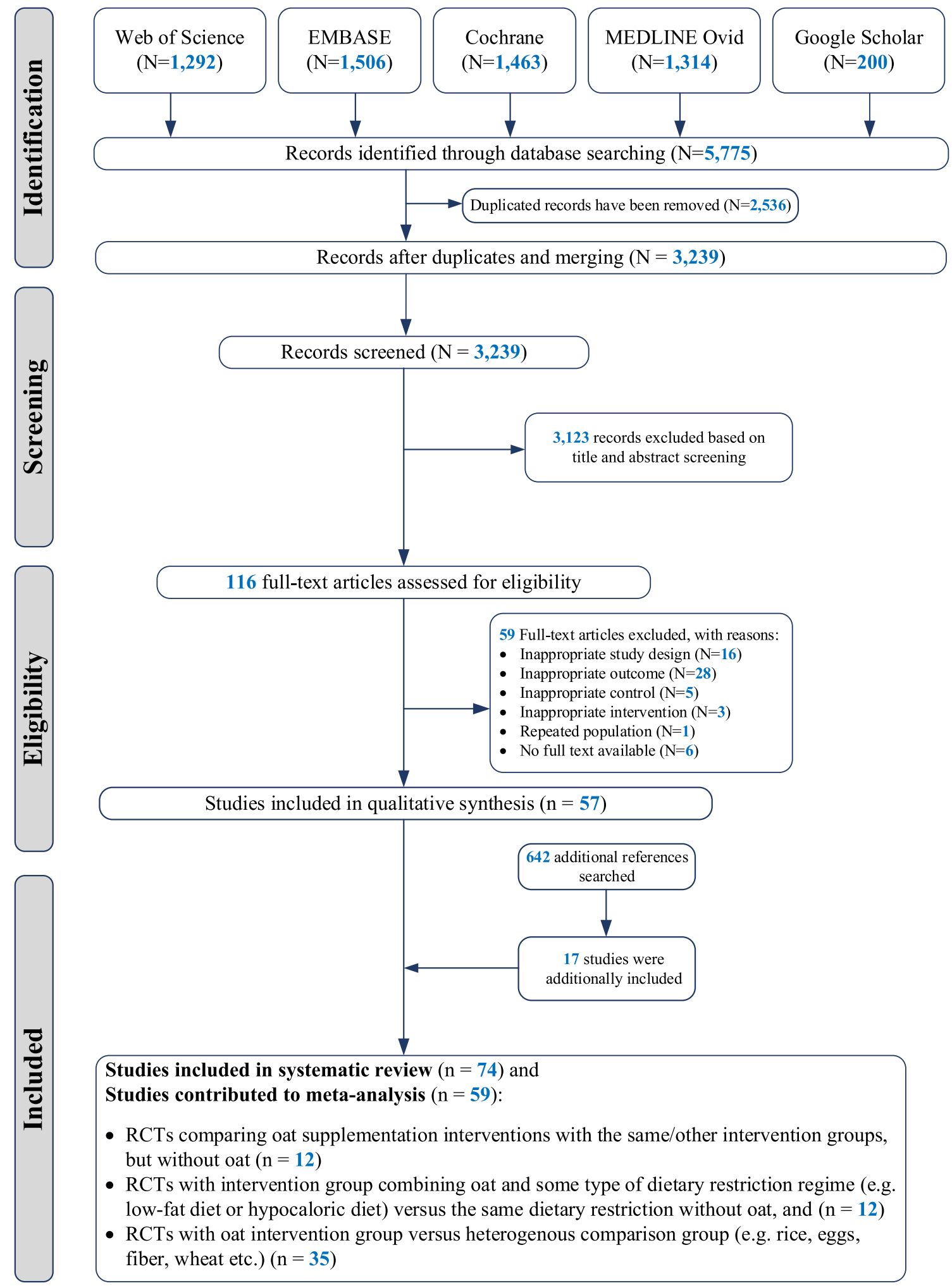

Fig. 1 PRISMA flowchart of selection process and included studies 


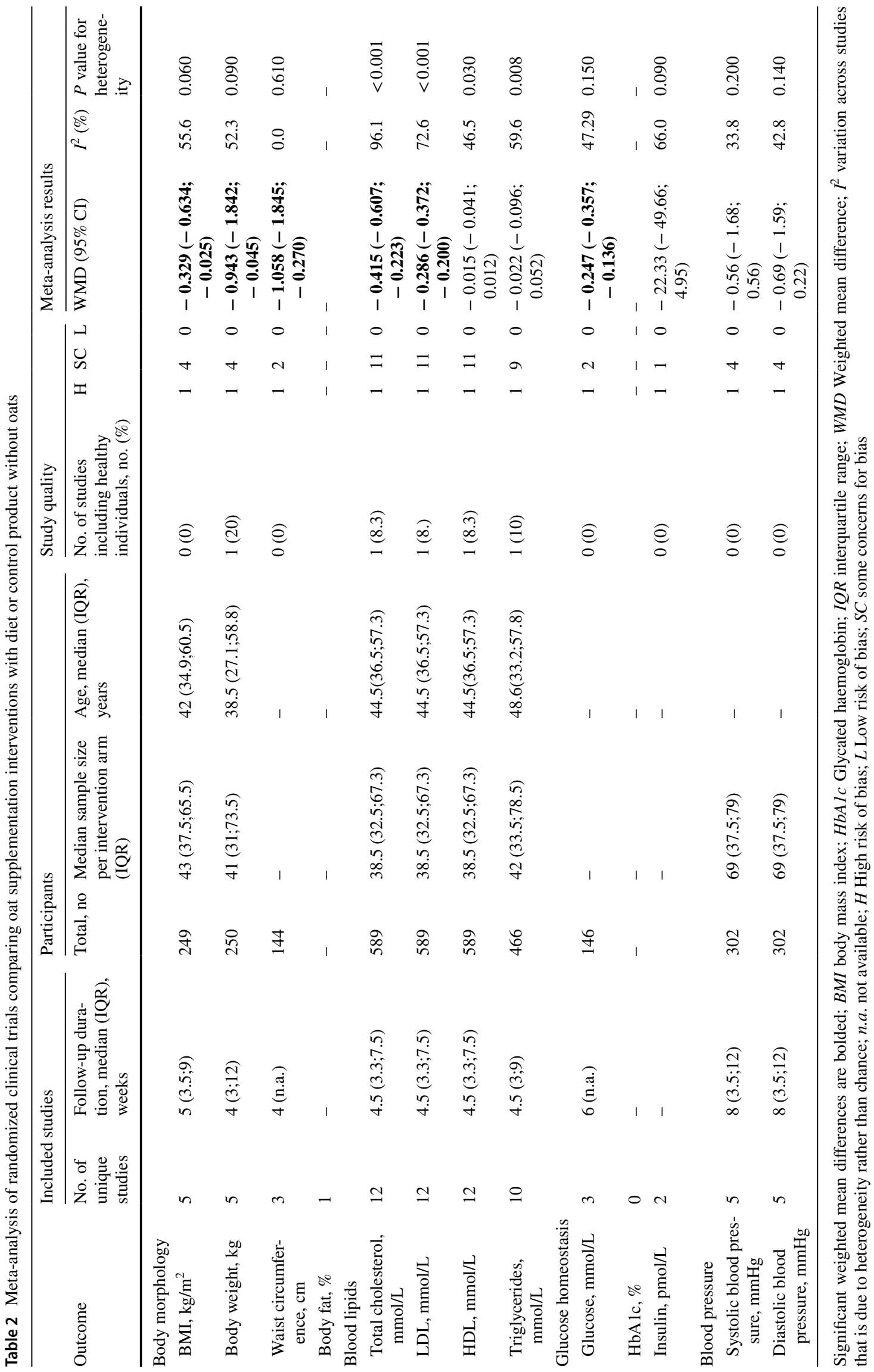




\section{Meta-analysis of RCTs comparing oat supplementation intervention combined with some type of dietary restriction versus the same dietary restriction alone}

Data from 12 RCTs were used to compare changes in CVD risk markers between intervention groups combining an OSI with some type of DR versus DR alone. When pooling the estimates of these RCTs, we found that: (i) BMI [WMD: $\left.-0.13 \mathrm{~kg} / \mathrm{m}^{2}, 95 \% \mathrm{CI}(-0.26 ;-0.02), I^{2}=40 \%, \mathrm{Q}_{\mathrm{p}}=0.13\right]$, TC [WMD: $-0.43 \mathrm{mmol} / \mathrm{L}, 95 \% \mathrm{CI}(-0.56 ;-0.30)$, $\left.I^{2}=91.7 \%, \mathrm{Q}_{\mathrm{p}}<0.001\right]$, HDL-C [WMD: $-0.05 \mathrm{mmol} / \mathrm{L}$, $95 \%$ CI $\left.(-0.10 ;-0.006), I^{2}=97.1 \%, \mathrm{Q}_{\mathrm{p}}<0.001\right]$, and LDL-C [WMD: $-0.26 \mathrm{mmol} / \mathrm{L}, 95 \% \mathrm{CI}(-0.38 ;-0.14)$, $\left.I^{2}=94.1 \%, \mathrm{Q}_{\mathrm{p}}<0.001\right]$ were lower in the OSI + DR group compared to DR alone arm (Table 3). No differences were seen in apolipoproteins A and B between the two groups. In addition, $\mathrm{HbA} 1 \mathrm{c}$ and diastolic $\mathrm{BP}$ were lower in OSI + DR group compared to DR alone, with WMD of $-0.42 \mathrm{mmol} / \mathrm{L}$ $\left[(-0.48 ;-0.36), \mathrm{I}^{2}=0 \%, \mathrm{Q}_{\mathrm{p}}=0.76\right]$ and $-1.15 \mathrm{mmHg}$ $\left[(-2.03 ;-0.28), I^{2}=55.9 \%, \mathrm{Q}_{\mathrm{p}}=0.06\right]$, respectively (Table 3).

\section{Subgroup analysis, leave-one-out analysis and publication bias}

In subgroup analyses and meta-regression, only geographic location and sex were identified as potential sources of heterogeneity for TC and LDL-C analysis, respectively, (Supplemental Table 2). The leave-one-out analyses showed that findings on TC, HDL-C, LDL-C, TGs and glucose were not driven by any single study (Supplemental Tables 7-11). Regressing continuous variables, such as age, duration of study and number of study participants, on WMD showed some evidence of linear trends between percentage of male individuals and WMD of HDL-C and LDL-C. With increasing proportions of male participants, WMD of LDL-C $(p=0.03)$ and TC $(p=0.51)$ tended to decrease, but WMD of HDL-C increased $(p=0.007)$, Supplemental Figs. 5-8. No evidence was found for publication bias of RCTs included in meta-analysis comprising five or more estimates (Supplemental Figs. 17-22).

\section{Meta-analysis of RCTs comparing oat supplementation intervention versus heterogeneous control arms}

A separate meta-analysis was performed including only 35 RCTs comparing CVD risk marker changes in an OSI vs. heterogeneous controls (e.g., rice, eggs, fibre, wheat, etc.). Results on blood lipid parameters remained similar to the other two meta-analyses, showing lowered TC and LDL-C in an OSI group compared to the control arms (Table 4).
In addition, TGs [WMD: $-0.06 \mathrm{mmol} / \mathrm{L}, 95 \% \mathrm{CI}(-0.10$; $-0.02)$ ] and apolipoprotein B [WMD: $-0.03 \mathrm{~g} / \mathrm{L}, 95 \% \mathrm{CI}$ $(-0.05 ;-0.01)]$ were significantly lower in the OSI arm compared to the control arm (Table 4). We found no differences for the rest of the investigated risk markers (Table 4).

\section{Qualitative data synthesis}

The scarcity of studies and the diversity of control arms across trials did not permit a meta-analysis of inflammation and oxidative stress markers. A summary of these results is available in Table 1.

In one study [20], daily supplementation of the diet with oat porridge containing $3 \mathrm{~g}$ of beta-glucan, among hypercholesterolemic adults, for 4 weeks resulted in decreased inflammatory marker levels, including high sensitivity $\mathrm{C}$-reactive protein (hsCRP), interleukin 8 (IL-8), IL-6, and tumour necrosis factor alpha (TNF- $\alpha$ ). The OSI also increased antioxidant capacities, by increasing the oxygen radical absorbance capacity and ferric reducing ability of plasma. Consumption of rice porridge did not lead to significant changes in these measures [20]. Oat interventions differ by botanical origin, molar mass, food matrix or degree of purification, and thus may have different effects on inflammatory markers [21]. In a trial including 75 hypercholesterolemic subjects receiving either $6 \mathrm{~g} / \mathrm{d}$ concentrated OßGREs or $6 \mathrm{~g} / \mathrm{d}$ dextrose (control) over a 6-week period, hsCRP did not significantly change in response to OBGREs [22]. Similarly, in an RCT comparing a mixture of wheat and oats with wheat only, none of the treatments significantly affected hsCRP or IL-6 [23]. In 43 otherwise healthy men and women with increased cholesterol levels, who consumed a daily ready-meal soup low in energy and fat and high in fibre, but with OßGREs vs. the same soup without $O \beta G R E s$, there were no statistically significant changes observed in hsCRP between groups [24]. A single study on the antioxidant effects of avenanthramides was found: healthy people were randomized to the OSI group with oats-derived avenanthramides capsules (containing $3.12 \mathrm{mg}$ avenanthramides) or placebo (corn oil capsules) or control group (no avenanthramides) for 1 month. Reported post-treatment serum levels of superoxide dismutase and reduced glutathione were found to significantly increase by $8.4 \%$ and $17.9 \%$, respectively $(p<0.05)$ [25]. While malondialdehyde level significantly decreased by $28.1 \%$, TC, TG and LDL-C levels were lowered by $11.1 \%, 28.1 \%$, and $15.1 \%$ compared to no oats and control groups, respectively.

\section{Discussion}

In this systematic review and meta-analysis, dietary OSIs were associated with some improvements in a subset of CVD risk markers independently of the dietary background 


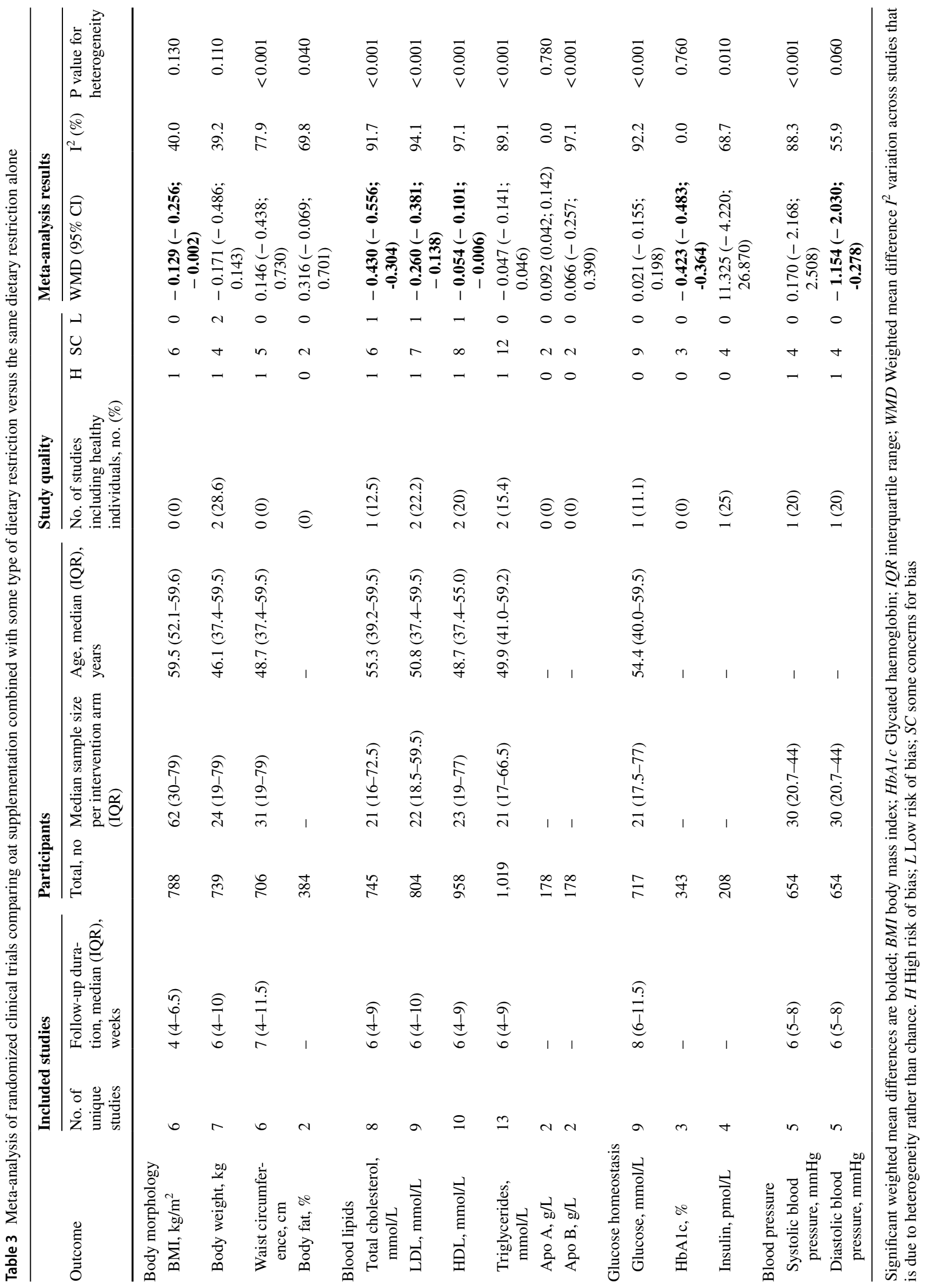




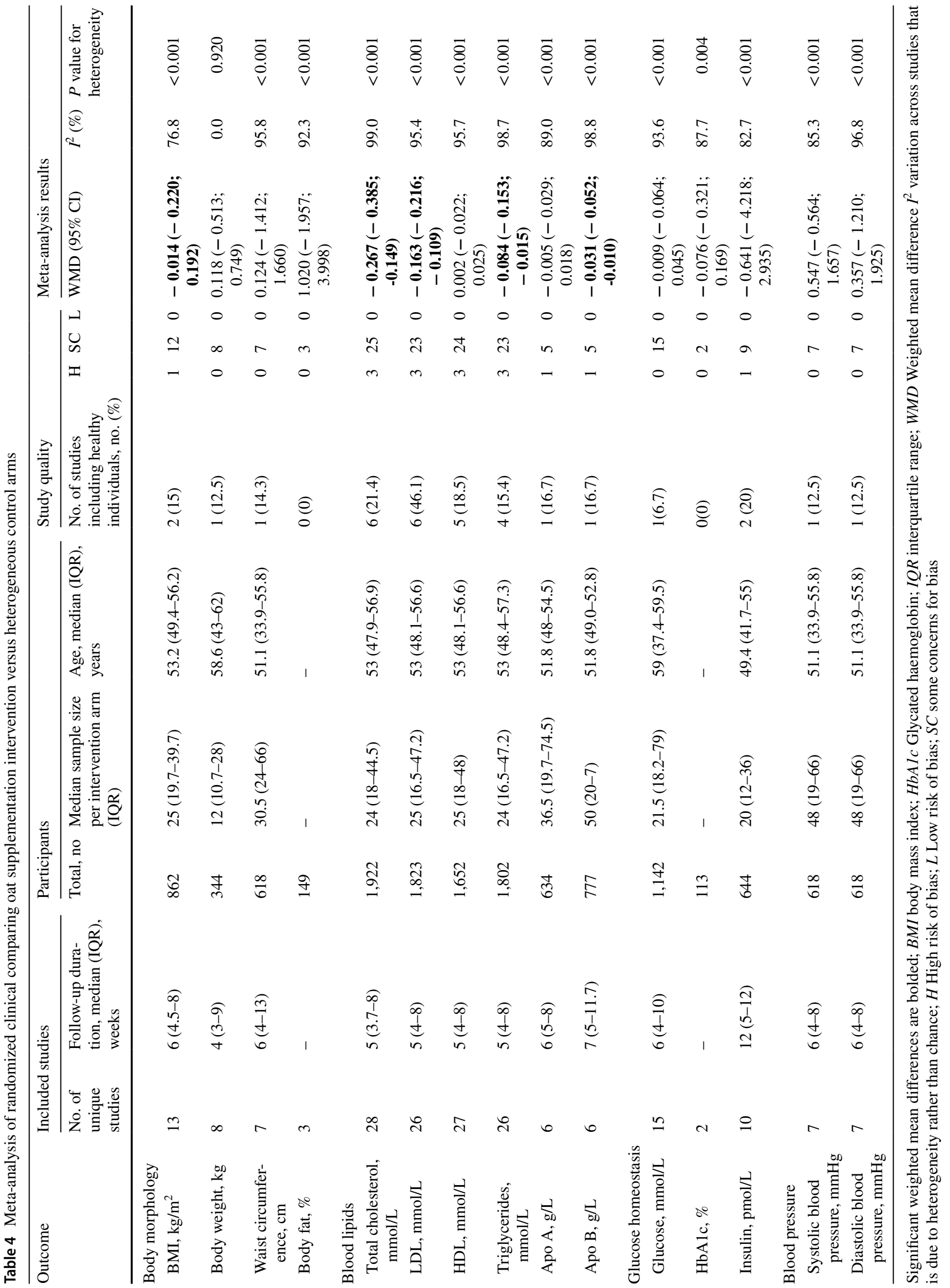




\section{RANDOMIZED CONTROLLED TRIALS (RCTS) WITH AN OAT SUPPLEMENTATION INTERVENTION (OSI)}
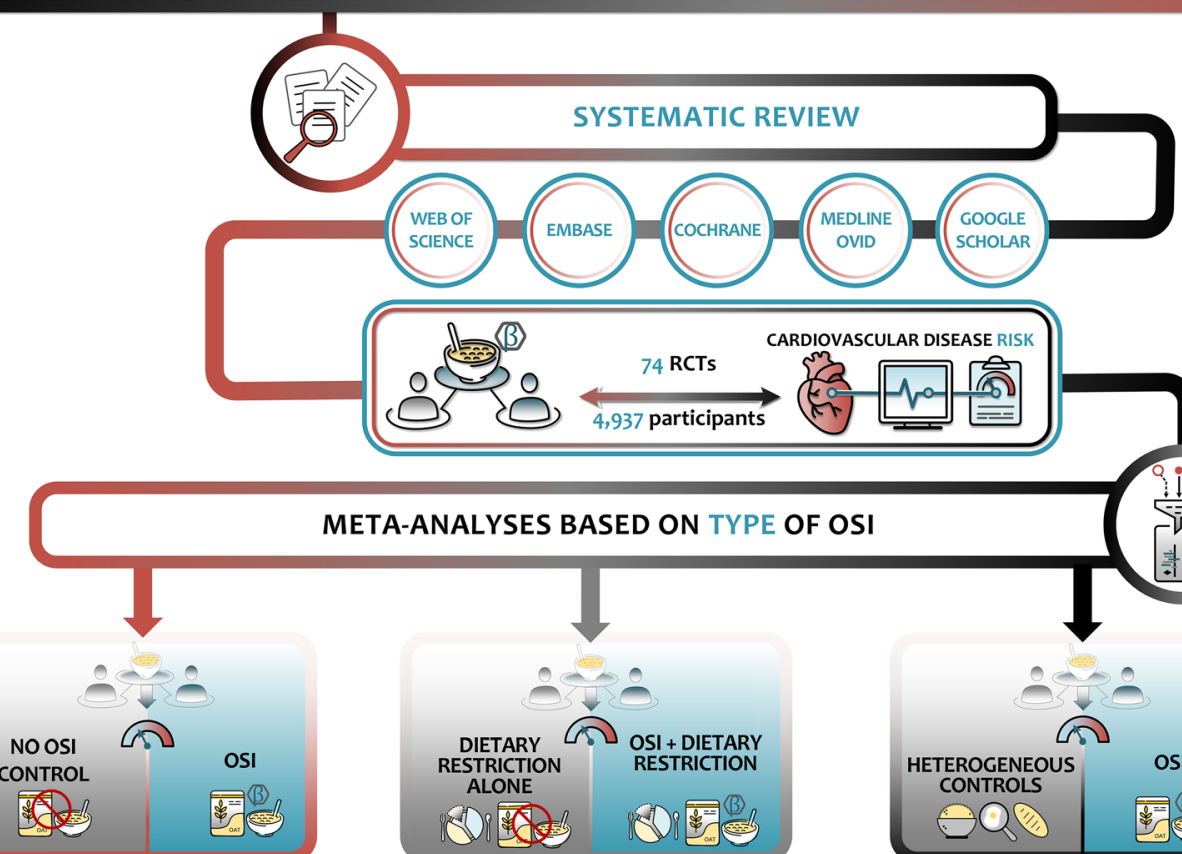

$\mathrm{N}=12$ RCTs
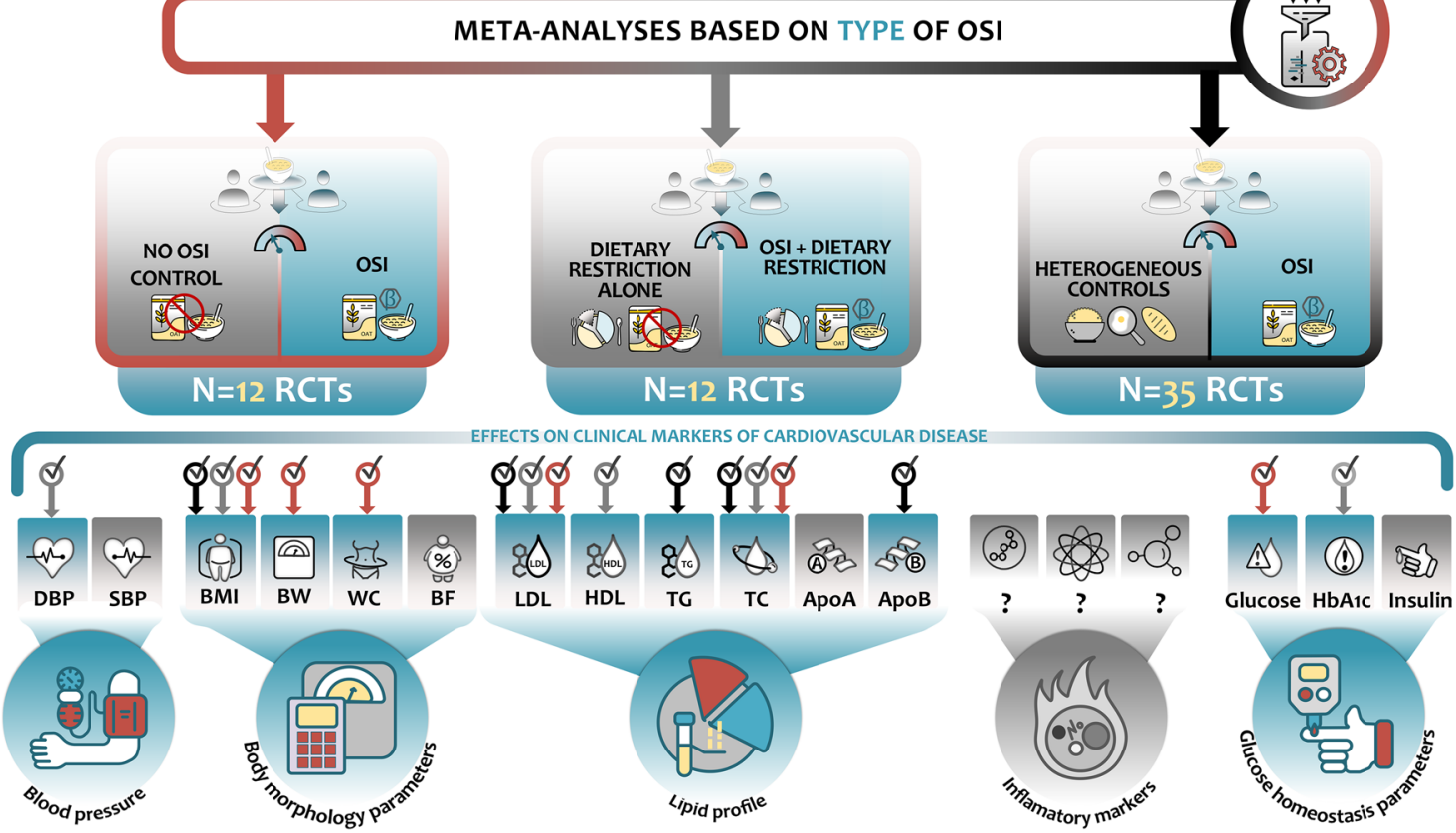

Notes: ApoA: apolipoprotein A; ApoB: apolipoprotein B; TC: total cholesterol; LDL: low-density lipoprotein; HDL: high-density lipoprotein; TG: triglycerides; BF: body fatness; WC: waist circumference; BW: body weight; BMI: body mass index; SBP: systolic blood pressure; DBP: diastolic blood pressure; HbA1c: Glycated haemoglobin. Icons in grey at clinical endpoint level indicate that no effect or association was found.

(3):Oat beta-glucan extract $Q$ :significant reduction effect. Colour of arrow and circle indicates the type of intervention that the effect was confirmed

Fig. 2 Graphical summary of main findings

or control arm (Fig. 2). In particular, OSIs showed consistent decreases for BMI, total and LDL-C levels, regardless of the background diet or comparison group. OSIs lowered levels of HbA1c, diastolic BP and HDL-C only when compared to no OSIs. Furthermore, compared to heterogeneous control arms, potential benefits of oat dietary supplementation on apolipoprotein B and TG levels were observed, in addition to improved TC and LDL-C levels. A network meta-analysis has also suggested that OSIs can help regulate TC and LDL$\mathrm{C}$, indicating that increasing oat sources of whole grain may be recommended for lipid control [26].

Findings of meta-analyses have shown that intake of oat products can lower blood lipids, mainly serum LDL-C concentrations, but with a relatively modest reductions, which were variable within the range of real-world intakes. The role of oat products on lipid profile has been extensively studied in previous meta-analyses of RCTs, involving normal or mildly hypercholesterolaemic adults $[6,11,27$, 28]. Our meta-analysis included a larger number of studies, stratified the effects of an OSI by whether it was combined with another dietary restriction and demonstrated the beneficial effects of an OSI despite background diet or control arm.

Oats can exert health benefits via bioactive phytochemicals with potent antioxidant and anti-inflammatory effects, such as phytosterols, tocols, flavonoids, avenanthramides and soluble fibres such as beta-glucans [29, 30]. The 
cholesterol-lowering effects of soluble fibres can be partially explained by the modulating effect on absorption and re-absorption of cholesterol and bile acids due to their binding to fibre [31], or by the increased viscosity [32], which may modify the process of mixing, diffusion and/or emulsification in the gastrointestinal tract [33]. Soluble viscous fibres can influence dietary lipid metabolism in the mildly acidic medium found in the stomach [34]. Further, OßGREs have been shown to lower insulin release, which in turn can lower serum cholesterol levels [35]. Propionate produced by fermentation in the colon may inhibit cholesterol synthesis in the liver $[35,36]$. This systemic interplay of oat bioactive phytochemicals and soluble fibres such as beta-glucans could have the potential to influence cardiometabolic health directly and indirectly, which warrants further investigation [4].

Apart from the lowering effect of an OSI on TC and LDL$\mathrm{C}$, a significant decrease in HDL-C was observed in the meta-analysis of RCTs comparing OSI + DR vs. DR alone. A recent RCT [37] has reported a similar HDL-C-lowering effect among patients with metabolic syndrome, in line with an RCT in 2010 [38]. This decrease in HDL-C may be linked to the background diet in the OSI group, which may have been unfavourable or influenced by confounding factors. Clinical and epidemiologic studies have established the presence of an inverse relationship between HDL-C levels and CVD risk, assuming that increased HDL-C levels are linked to protective effects on CVD [39, 40]. However, there is no sufficient evidence to show cardiovascular benefit of an OSI in patients on cholesterol-lowering therapy (e.g., statins), suggesting that HDL-C increases may not be sufficient to influence CVD risk, when LDL-C is kept in relatively low levels [41-43]. In addition, most research on HDL-C and Mendelian randomization studies have failed to find a direct effect of HDL-C on CVDs [41, 44]. However, it is reasonable to assume that we cannot ascertain the cause of this decrease in HDL-C and the role it may have on assessing the overall impact of oat intake on CVD risk. Future studies should explore how oat intake may affect different types of HDL-C particles, such as small-sized HDL-C, as well as their implications on cardiometabolic health [45].

A growing body of epidemiological studies [46-51] has consistently shown an inverse relationship between dietary fibre intake (such as those found in oats) and body weight. This report found a significant change in BMI, body weight and WC in the main meta-analysis. We observed similar effects and direction for BMI in the pooled analyses of OSIs + DR vs. DR alone. These findings suggest that the extent of health effects of an OSI on body morphology may be highly dependent on the background diet. When considering the effects of OSIs on BMI, body weight and/or WC, it is important to consider EFSA's scientific requirements for health claims related to such parameters [52]. In particular, it should be taken into consideration that the duration of an intervention required to evaluate body weight should be at least 12 weeks and imaging data by established techniques (e.g., dual energy X-ray absorptiometry, magnetic resonance imaging or computed tomography) are generally appropriate to assess changes in body composition in human intervention studies. In our systematic review there were 20 RCTs with a duration of 12 weeks or more. In addition, not all interventions in RCTs were isocaloric, thus limiting our understanding of the impact of OSIs on obesity. Future clinical trials are needed to help address this question.

Effects of an OSI on BP were only observed for diastolic BP, in the case of OSI + DR vs. DR alone. This change (i.e., WMD: $-1.15 \mathrm{~mm} \mathrm{Hg}$, 95\% CI $(-2.03 ;-0.28)$ ) was inconsistent in other types of interventions and not found in case of systolic BP. A similar inconsistency was observed for glucose homeostasis markers, where significant differences were observed for HbA1c only in RCTs comparing OSI + DR versus DR alone and for glucose for RCTs comparing OSIs vs. no OSIs. No significant differences were observed in any other intervention or in interventions comparing an OSI with heterogeneous controls, regarding any glucose homeostasis marker. A meta-analysis of RCTs evaluating the effects of oat products on glycaemic control among diabetic patients indicated that the effects of oats and oat beta-glucans on glycaemic control and insulin sensitivity are inconclusive [5]. In line with our work, a systematic review on oat intake and its association with CVD risk markers did not find convincing evidence of oat influence on insulin sensitivity and emphasized the importance of exploring additional CVD markers [4]. However, it has been proposed that the glycaemic benefits of oats are directly dependent on the structural integrity of the oat kernel, $\beta$-glucan's dose, molecular weight and comparison [13, 53-55]. Even though our findings were based on a limited number of studies focused on OSIs and glucose homeostasis, they still suggest some benefits for the later and thus warrant the need for further more rigorous research.

\section{Strengths, limitations and recommendations for future research}

To the best of our knowledge, this is the first study to provide a comprehensive analysis on the role of OSI on several CVD risk markers, accounting for background diet and control arms. To identify as many relevant studies as possible and reduce the risk of publication bias, a highly sensitive search strategy was used and additional resources were searched including the reference lists of included trials and relevant systematic reviews. Conventional funnel plots and Egger test estimates showed only a minimal publication bias; still, these methods are limited by their qualitative nature and we cannot exclude the possibility of measured or unmeasured 
publication bias. Location of study and percentage of male participants contributed to the heterogeneity of findings, and the OSI's dose and duration were highly variable. Thus, future studies exploring the role of sex, ethnicity and cultural factors in the association of OSIs and risk of CVD are warranted. Our findings need to be interpreted cautiously, with considerations of the specific comparison food/diet. Also, only 36 out of 74 RCTs (48.6\%) took isocaloric diet between arms into account, and whether these differences affect the results should be explored by future studies.

\section{Conclusion}

Supplementation of diet with oat cereals improves CVD risk markers among healthy adults and those with mild metabolic disturbances, particularly by influencing serum total and LDL cholesterol, BMI and WC. The beneficial effects on TC and LDL-C were independent of the dietary background. The role of OSIs on BP, glucose homeostasis or other markers, could not be established.

Supplementary Information The online version contains supplementary material available at https://doi.org/10.1007/s00394-021-02763-1.

Author contributions All authors provided inputs and agreed on the final version of the manuscript. TM and HK conceptualized the research and supervised the project administration. EL and GD were involved in the screening process of abstracts, assessing full-text articles for eligibility, data extraction and quality assessment of included studies and contributed to writing the first draft of the manuscript. MG and TM were involved in all the phases of the literature search, study selection procedure, interpretation the results and guided the writing of the manuscript. EL, HK, TV, PMV, BeM and AB were involved in reviewing the manuscript and in finalizing it. $\mathrm{AB}$ was also involved in quality assessment. EL, HK, EV, MG, LK, SS, JS and BrM participated data extraction, synthesis and interpretation, as well as in providing editorial and medical writing assistance. EL designed the graphical summary.

Funding This research was supported by Standard Process Inc. Brandon Metzger and Hua Kern are scientists at Standard Process Nutrition Innovation Centre. Erand Llanaj was supported by the Hungarian Academy of Sciences (TK2016-78) and the National Research, Development and Innovation Fund of Hungary, financed under the K_20 funding scheme (Project no. 135784). All other authors have nothing to disclose. The sponsor did not participate in the conduct of the study and the collection, management, analysis, and interpretation of the data. Preparation, review, and approval of the manuscript and the decision to submit the manuscript for publication were undertaken by authors. The sponsors did not have the right to veto publication or to control the decision.

\section{Declarations}

Conflict of interest Hua Kern and Brandon Metzger were employees of Standard Process Inc. at the time of the manuscript's development, writing and submission. Standard Process provided support in the form of personal fee for author TM and paid the fee for the publication. All other authors declare that they have no known competing financial in- terests or personal relationships that could have appeared to influence the work reported in this paper.

Ethical approval Not applicable.

Consent to participate Not applicable.

Open Access This article is licensed under a Creative Commons Attribution 4.0 International License, which permits use, sharing, adaptation, distribution and reproduction in any medium or format, as long as you give appropriate credit to the original author(s) and the source, provide a link to the Creative Commons licence, and indicate if changes were made. The images or other third party material in this article are included in the article's Creative Commons licence, unless indicated otherwise in a credit line to the material. If material is not included in the article's Creative Commons licence and your intended use is not permitted by statutory regulation or exceeds the permitted use, you will need to obtain permission directly from the copyright holder. To view a copy of this licence, visit http://creativecommons.org/licenses/by/4.0/.

\section{References}

1. Arnett DK, Khera A, Blumenthal RS (2019) 2019 ACC/AHA guideline on the primary prevention of cardiovascular disease: part 1, lifestyle and behavioral factors. JAMA Cardiol 4(10):1043-1044. https://doi.org/10.1001/jamacardio.2019.2604

2. U. S. Preventive Services Task Force (2020) Behavioral counseling interventions to promote a healthy diet and physical activity for cardiovascular disease prevention in adults with cardiovascular risk factors: US preventive services task force recommendation statement. JAMA 324(20):2069-2075. https:// doi.org/10.1001/jama.2020.21749

3. Mathews R, Kamil A, Chu Y (2020) Global review of heart health claims for oat beta-glucan products. Nutr Rev 78(Supplement_1):78-97. https://doi.org/10.1093/nutrit/nuz069

4. Thies F, Masson LF, Boffetta P, Kris-Etherton P (2014) Oats and CVD risk markers: a systematic literature review. Br J Nutr 112(S2):S19-S30. https://doi.org/10.1017/S0007114514002281

5. Shen XL, Zhao T, Zhou Y, Shi X, Zou Y, Zhao G (2016) Effect of oat $\beta$-glucan intake on glycaemic control and insulin sensitivity of diabetic patients: A meta-analysis of randomized controlled trials. Nutrients 8(1):39. https://doi.org/10.3390/nu8010039

6. Ho HV, Sievenpiper JL, Zurbau A, Blanco Mejia S, Jovanovski E, Au-Yeung F, Jenkins AL, Vuksan V (2016) The effect of oat $\beta$-glucan on LDL-cholesterol, non-HDL-cholesterol and apoB for CVD risk reduction: a systematic review and meta-analysis of randomised-controlled trials. Br J Nutr 116(8):1369-1382. https://doi.org/10.1017/s000711451600341x

7. Tosh SM (2013) Review of human studies investigating the postprandial blood-glucose lowering ability of oat and barley food products. Eur J Clin Nutr 67(4):310-317. https://doi.org/10.1038/ ejen.2013.25

8. Helnæs A, Kyrø C, Andersen I, Lacoppidan S, Overvad K, Christensen J, Tjønneland A, Olsen A (2016) Intake of whole grains is associated with lower risk of myocardial infarction: the Danish Diet, Cancer and Health Cohort. Am J Clin Nutr 103(4):999_ 1007. https://doi.org/10.3945/ajen.115.124271

9. Rebello CJ, O'Neil CE, Greenway FL (2016) Dietary fiber and satiety: the effects of oats on satiety. Nutr Rev 74(2):131-147. https://doi.org/10.1093/nutrit/nuv063

10. Li X, Cai X, Ma X, Jing L, Gu J, Bao L, Li J, Xu M, Zhang Z, Li $Y$ (2016) Short- and long-term effects of wholegrain oat intake on weight management and glucolipid metabolism in overweight 
type-2 diabetics: a randomized control trial. Nutrients. https:// doi.org/10.3390/nu8090549

11. Whitehead A, Beck EJ, Tosh S, Wolever TMS (2014) Cholesterol-lowering effects of oat $\beta$-glucan: a meta-analysis of randomized controlled trials. Am J Clin Nutr 100(6):1413-1421. https://doi.org/10.3945/ajen.114.086108

12. Marshall S, Petocz P, Duve E, Abbott K, Cassettari T, Blumfield M, Fayet-Moore F (2020) The effect of replacing refined grains with whole grains on cardiovascular risk factors: a systematic review and meta-analysis of randomized controlled trials with GRADE clinical recommendation. J Acad Nutr Diet 120(11):1859-1883.e1831. https://doi.org/10.1016/j.jand.2020. 06.021

13. Musa-Veloso K, Noori D, Venditti C, Poon T, Johnson J, Harkness LS, O'Shea M, Chu Y (2020) A systematic review and meta-analysis of randomized controlled trials on the effects of oats and oat processing on postprandial blood glucose and insulin responses. J Nutr. https://doi.org/10.1093/jn/nxaa349

14. Muka T, Glisic M, Milic J, Verhoog S, Bohlius J, Bramer W, Chowdhury R, Franco OH (2020) A 24-step guide on how to design, conduct, and successfully publish a systematic review and meta-analysis in medical research. Eur J Epidemiol. https:// doi.org/10.1007/s10654-019-00576-5

15. Moher D, Liberati A, Tetzlaff J, Altman DG, Group P (2009) Preferred reporting items for systematic reviews and meta-analyses: the PRISMA statement. PLoS medicine 6(7):e1000097. https:// doi.org/10.1371/journal.pmed.1000097

16. Sterne JAC, Savović J, Page MJ, Elbers RG, Blencowe NS, Boutron I, Cates CJ, Cheng H-Y, Corbett MS, Eldridge SM, Hernán MA, Hopewell S, Hróbjartsson A, Junqueira DR, Jüni P, Kirkham JJ, Lasserson T, Li T, McAleenan A, Reeves BC, Shepperd S, Shrier I, Stewart LA, Tilling K, White IR, Whiting PF, JPT H (2019) RoB 2: a revised tool for assessing risk of bias in randomised trials. BMJ 366:14898. https://doi.org/10.1136/ bmj.14898

17. Hozo SP, Djulbegovic B, Hozo I (2005) Estimating the mean and variance from the median, range, and the size of a sample. BMC Med Res Methodol 5:13. https://doi.org/10.1186/1471-2288-5-13

18. Higgins JP, Thompson SG, Deeks JJ, Altman DG (2003) Measuring inconsistency in meta-analyses. BMJ 327(7414):557-560. https://doi.org/10.1136/bmj.327.7414.557

19. Thompson SG, Sharp SJ (1999) Explaining heterogeneity in meta-analysis: a comparison of methods. Stat Med 18(20):2693-2708

20. Pavadhgul P, Bumrungpert A, Harjani Y, Kurilich A (2019) Oat porridge consumption alleviates markers of inflammation and oxidative stress in hypercholesterolemic adults. Asia Pac J Clin Nutr 28(2):260-265. https://doi.org/10.6133/apjcn.201906_ 28(2).0008

21. Vetvicka V, Vannucci L, Sima P, Richter J (2019) Beta glucan: supplement or drug? From laboratory to clinical trials. Molecules. https://doi.org/10.3390/molecules24071251

22. Queenan KM, Stewart ML, Smith KN, Thomas W, Fulcher RG, Slavin JL (2007) Concentrated oat beta-glucan, a fermentable fiber, lowers serum cholesterol in hypercholesterolemic adults in a randomized controlled trial. Nutr J 6:6. https://doi.org/10. 1186/1475-2891-6-6

23. Tighe P, Duthie G, Vaughan N, Brittenden J, Simpson WG, Duthie $S$ et al (2010) Effect of increased consumption of wholegrain foods on blood pressure and other cardiovascular risk markers in healthy middle-aged persons: a randomized controlled trial. Am J Clin Nutr 92(4):733-740. https://doi.org/10.3945/ ajcn.2010.29417

24. Biorklund M, Holm J, Onning G (2008) Serum lipids and postprandial glucose and insulin levels in hyperlipidemic subjects after consumption of an oat beta-glucan-containing ready meal.
Ann Nutr Metab 52(2):83-90. https://doi.org/10.1159/00012 1281

25. Liu S, Yang N, Hou Z-h, Yao Y, Lu L, Zhou X-R, Ren G (2011) Antioxidant effects of oats avenanthramides on human serum. Agr Sci China 10:1301-1305. https://doi.org/10.1016/S16712927(11)60122-3

26. Hui S, Liu K, Lang H, Liu Y, Wang X, Zhu X, Doucette S, Yi L, Mi M (2019) Comparative effects of different whole grains and brans on blood lipid: a network meta-analysis. Eur J Nutr 58(7):2779-2787. https://doi.org/10.1007/s00394-018-1827-6

27. Ripsin CM, Keenan JM, Jacobs DR Jr, Elmer PJ, Welch RR, Van Horn L, Liu K, Turnbull WH, Thye FW, Kestin M et al (1992) Oat products and lipid lowering. A meta-analysis. JAMA 267(24):3317-3325

28. Brown L, Rosner B, Willett WW, Sacks FM (1999) Cholesterollowering effects of dietary fiber: a meta-analysis. Am J Clin Nutr 69(1):30-42. https://doi.org/10.1093/ajen/69.1.30

29. Bernstein AM, Titgemeier B, Kirkpatrick K, Golubic M, Roizen MF (2013) Major cereal grain fibers and psyllium in relation to cardiovascular health. Nutrients 5(5):1471-1487. https://doi.org/ 10.3390/nu5051471

30. Francis Raguindin P, Adam Itodo O, Stoyanov J, Dejanovic GM, Gamba M, Asllanaj E, Minder B, Bussler W, Metzger B, Muka T, Glisic M, Kern H (2020) A systematic review of phytochemicals in oat and buckwheat. Food Chem. https://doi.org/10.1016/j. foodchem.2020.127982

31. Braaten JT, Wood PJ, Scott FW, Wolynetz MS, Lowe MK, Bradley-White P, Collins MW (1994) Oat beta-glucan reduces blood cholesterol concentration in hypercholesterolemic subjects. Eur J Clin Nutr 48(7):465-474

32. Sawicki CM, McKay DL, McKeown NM, Dallal G, Chen CYO, Blumberg JB (2016) Phytochemical pharmacokinetics and bioactivity of oat and barley flour: a randomized crossover trial. Nutrients 8(12):813. https://doi.org/10.3390/nu8120813

33. Wood PJ (2010) Oat and rye $\beta$-glucan: properties and function. Cereal Chem 87(4):315-330. https://doi.org/10.1094/ CCHEM-87-4-0315

34. Pasquier B, Armand M, Castelain C, Guillon F, Borel P, Lafont H, Lairon D (1996) Emulsification and lipolysis of triacylglycerols are altered by viscous soluble dietary fibres in acidic gastric medium in vitro. Biochem J 314(1):269-275. https://doi.org/10. 1042/bj3140269

35. Chen J, Raymond K (2008) Beta-glucans in the treatment of diabetes and associated cardiovascular risks. Vasc Health Risk Manag 4(6):1265. https://doi.org/10.2147/VHRM.S3803

36. Joyce SA, Kamil A, Fleige L, Gahan CGM (2019) The cholesterol-lowering effect of oats and oat beta glucan: modes of action and potential role of bile acids and the microbiome. Front Nutr 6:171. https://doi.org/10.3389/fnut.2019.00171

37. Leão LSCdS, Aquino LAd, Dias JF, Koifman RJ (2019) Addition of oat bran reduces HDL-C and does not potentialize effect of a low-calorie diet on remission of metabolic syndrome: a pragmatic, randomized, controlled, open-label nutritional trial. Nutrition 65:126-130. https://doi.org/10.1016/j.nut.2019.03.007

38. Beck EJ, Tapsell LC, Batterham MJ, Tosh SM, Huang XF (2010) Oat beta-glucan supplementation does not enhance the effectiveness of an energy-restricted diet in overweight women. Br J Nutr 103(8):1212-1222. https://doi.org/10.1017/s0007114509992856

39. Gordon DJ, Rifkind BM (1989) High-density lipoproteinthe clinical implications of recent studies. N Engl J Med 321(19):1311-1316. https://doi.org/10.1056/NEJM19891109321 1907

40. Wilson PW, Abbott RD, Castelli WP (1988) High density lipoprotein cholesterol and mortality. The Framingham Heart Study. Arteriosclerosis 8(6):737-741. https://doi.org/10.1161/01.atv.8. 6.737 
41. Voight BF, Peloso GM, Orho-Melander M, Frikke-Schmidt R, Barbalic M, Jensen MK et al (2012) Plasma HDL cholesterol and risk of myocardial infarction: a mendelian randomisation study. Lancet 380(9841):572-580. https://doi.org/10.1016/S01406736(12)60312-2

42. Frikke-Schmidt R, Nordestgaard BG, Stene MC, Sethi AA, Remaley AT, Schnohr P, Grande P, Tybjaerg-Hansen A (2008) Association of loss-of-function mutations in the ABCA1 gene with high-density lipoprotein cholesterol levels and risk of ischemic heart disease. JAMA 299(21):2524-2532. https://doi. org/10.1001/jama.299.21.2524

43. Zanoni P, Khetarpal SA, Larach DB, Hancock-Cerutti WF, Millar JS, Cuchel M et al (2016) Rare variant in scavenger receptor BI raises HDL cholesterol and increases risk of coronary heart disease. Science 351(6278):1166-1171. https://doi.org/10.1126/ science. $\operatorname{aad} 3517$

44. Lind L, Ingelsson M, Sundstrom J, Ärnlöv J (2021) Impact of risk factors for major cardiovascular diseases: a comparison of life-time observational and Mendelian randomisation findings. Open heart. https://doi.org/10.1136/openhrt-2021-001735

45. Duparc T, Ruidavets J-B, Genoux A, Ingueneau C, Najib S, Ferrières J, Perret B, Martinez LO (2020) Serum level of HDL particles are independently associated with long-term prognosis in patients with coronary artery disease: The GENES study. Sci Rep 10(1):8138. https://doi.org/10.1038/s41598-020-65100-2

46. Davis JN, Hodges VA, Gillham MB (2006) Normal-weight adults consume more fiber and fruit than their age- and height-matched overweight/obese counterparts. J Am Diet Assoc 106(6):833840. https://doi.org/10.1016/j.jada.2006.03.013

47. Koh-Banerjee P, Franz M, Sampson L, Liu S, Jacobs DR Jr, Spiegelman D, Willett W, Rimm E (2004) Changes in wholegrain, bran, and cereal fiber consumption in relation to 8-y weight gain among men. Am J Clin Nutr 80(5):1237-1245. https://doi. org/10.1093/ajen/80.5.1237

48. Liu S, Willett WC, Manson JE, Hu FB, Rosner B, Colditz G (2003) Relation between changes in intakes of dietary fiber and grain products and changes in weight and development of obesity among middle-aged women. Am J Clin Nutr 78(5):920-927. https://doi.org/10.1093/ajen/78.5.920

49. Howarth NC, Saltzman E, Roberts SB (2001) Dietary fiber and weight regulation. Nutr Rev 59(5):129-139. https://doi.org/10. 1111/j.1753-4887.2001.tb07001.x

50. Miller WC, Niederpruem MG, Wallace JP, Lindeman AK (1994) Dietary fat, sugar, and fiber predict body fat content. J Am Diet Assoc 94(6):612-615. https://doi.org/10.1016/0002-8223(94) 90155-4

51. Jovanovski E, Mazhar N, Komishon A, Khayyat R, Li D, Blanco Mejia S, Khan T, Jenkins LA, Smircic-Duvnjak L, Sievenpiper LJ, Vuksan V (2020) Can dietary viscous fiber affect body weight independently of an energy-restrictive diet? A systematic review and meta-analysis of randomized controlled trials. Am J Clin Nutr 111(2):471-485. https://doi.org/10.1093/ajen/nqz292

52. EFSA Panel on Dietetic Products, Nutrition and Allergies (NDA); Guidance on the scientific requirements for health claims related to appetite ratings, weight management, and blood glucose concentrations. EFSA Journal 2021; 10 (3):2604 [11 p.]. doi:https:// doi.org/10.2903/j.efsa.2012.2604. Available online: www.efsa. europa.eu/efsajournal

53. Zurbau A, Noronha JC, Khan TA, Sievenpiper JL, Wolever TMS (2021) The effect of oat $\beta$-glucan on postprandial blood glucose and insulin responses: a systematic review and meta-analysis. Eur J Clin Nutr. https://doi.org/10.1038/s41430-021-00875-9

54. Fung TT, Hu FB, Pereira MA, Liu S, Stampfer MJ, Colditz GA, Willett WC (2002) Whole-grain intake and the risk of type 2 diabetes: a prospective study in men. Am J Clin Nutr 76(3):535540. https://doi.org/10.1093/ajcn/76.3.535
55. Kyro C, Tjonneland A, Overvad K, Olsen A, Landberg R (2018) Higher whole-grain intake is associated with lower risk of type 2 diabetes among middle-aged men and women: the Danish Diet, Cancer, and Health Cohort. J Nutr 148(9):1434-1444. https:// doi.org/10.1093/jn/nxy112

56. Abrahamsson L, Goranzon H, Karlstrom B, Vessby B, Aaman P (1994) Metabolic effects of oat bran and wheat bran in healthy women. Scand J Food Nutr: 38(1):5-10

57. Adamsson V, Reumark A, Marklund M, Larsson A, Risérus U (2015) Role of a prudent breakfast in improving cardiometabolic risk factors in subjects with hypercholesterolemia: a randomized controlled trial. Clin Nutr 34(1):20-26. https://doi.org/10.1016/j. clnu.2014.04.009

58. Amundsen ÅL, Haugum B, Andersson H (2003) Changes in serum cholesterol and sterol metabolites after intake of products enriched with an oat bran concentrate within a controlled diet. Scand J Food Nutr: 47(2):68-74. https://doi.org/10.1080/11026 480310009573

59. Anderson JW, Siesel AE (1990) Hypocholesterolemic Effects of Oat Products. In: Furda I, Brine CJ (eds) New Developments in Dietary Fiber, vol 270. Springer, Boston, MA

60. Anderson JW, Gilinsky NH, Deakins DA, Smith SF, O'Neal DS, Dillon DW, Oeltgen PR (1991) Lipid responses of hypercholesterolemic men to oat-bran and wheat-bran intake. Am J Clin Nutr. 54(4):678-83. https://doi.org/10.1093/ajcn/54.4.678

61. Anderson JW, Story L, Sieling B (1984) Hypocholesterolemic effects of oat-bran or bean intake for hypercholesterolemic men. Am J Clin Nutr 40(6):1146-1155. https://doi.org/10.1093/ajcn/ 40.6.1146

62. Ballesteros MN, Valenzuela F, Robles AE, Artalejo E, Aguilar D, Andersen CJ, Valdez H, Fernandez ML (2015) One egg per day improves inflammation when compared to an oatmeal-based breakfast without increasing other cardiometabolic risk factors in diabetic patients. Nutrients 7(5):3449-3463. https://doi.org/10. 3390/nu7053449

63. Beck EJ, Tapsell LC, Batterham MJ, Tosh SM, Huang XF (2010) Oat $\beta$-glucan supplementation does not enhance the effectiveness of an energy-restricted diet in overweight women. Br J Nutr 103(8):1212-1222. https://doi.org/10.1017/S0007114509992856

64. Berg A, König D, Deibert P, Grathwohl D, Berg A, Baumstark MW, Franz IW (2003) Effect of an oat bran enriched diet on the atherogenic lipid profile in patients with an increased coronary Heart Disease Risk: a controlled randomized lifestyle intervention Study. Ann Nutr Metab 47(6):306-311. https://doi.org/10. 1159/000072404

65. Biörklund M, Rees AV, Mensink R, Onning G (2005) Changes in serum lipids and postprandial glucose and insulin concentrations after consumption of beverages with beta-glucans from oats or barley: a randomised dose-controlled trial. Eur J Clin Nutr 59(11):1272-1281. https://doi.org/10.1038/sj.ejcn.1602240

66. Biörklund M, Holm J, Önning G (2008) Serum lipids and postprandial glucose and insulin levels in hyperlipidemic subjects after consumption of an oat $\beta$-glucan-containing ready meal. Ann Nutr Metab 52(2):83-90. https://doi.org/10.1159/000121281

67. Braaten JT, Wood PJ, Scott FW, Wolynetz MS, Lowe MK, Bradley-White P, Collins MW (1994) Oat $\beta$-glucan reduces blood cholesterol concentration in hypercholesterolemic subjects. Eur J Clin Nutr 48(7):465-474

68. Bremer JM, Scott RS, Lintott CJ (1991) Oat bran and cholesterol reduction: evidence against specific effect. Aust N Z J Med 21(4):422-426. https://doi.org/10.1111/j.1445-5994.1991.tb013 45. $\mathrm{x}$

69. Bridges SR, Anderson JW, Deakins DA, Dillon DW, Wood CL (1992) Oat bran increases serum acetate of hypercholesterolemic men. Am J Clin Nutr 56(2):455-459. https://doi.org/10.1093/ ajen/56.2.455 
70. Chang HC, Huang CN, Yeh DM, Wang SJ, Peng CH, Wang CJ (2013) Oat prevents obesity and abdominal fat distribution, and improves liver function in humans. Plant Foods Hum Nutr 68(1):18-23. https://doi.org/10.1007/s11130-013-0336-2

71. Chen J, He J, Wildman RP, Reynolds K, Streiffer RH, Whelton PK (2006) A randomized controlled trial of dietary fiber intake on serum lipids. Eur J Clin Nutr 60(1):62-68. https://doi.org/10. 1038/sj.ejen. 1602268

72. Connolly ML, Tzounis X, Tuohy KM, Lovegrove JA (2016) Hypocholesterolemic and prebiotic effects of a whole-grain oatbased granola breakfast cereal in a cardio-metabolic "at risk" population. Front Microbiol. https://doi.org/10.3389/fmicb.2016. 01675

73. Davy BM, Davy KP, Ho RC, Beske SD, Davrath LR, Melby CL (2002) High-fiber oat cereal compared with wheat cereal consumption favorably alters LDL-cholesterol subclass and particle numbers in middle-aged and older men. Am J Clin Nutr 76(2):351-358. https://doi.org/10.1093/ajcn/76.2.351

74. Raimondi de Souza S, Moraes de Oliveira GM, Raggio Luiz R, Rosa G (2016) Effects of oat bran and nutrition counseling on the lipid and glucose profile and anthropometric parameters of hypercholesterolemia patients. Nutr Hosp 33(1):123-130. https:// doi.org/10.20960/nh.40

75. Dubois C, Cara L, Borel P, Armand M, Senft M, Portugal H, Bernard P-M, Lafont H, Lairon D (1993) Cereal dietary fibers affect post-prandial lipoproteins in healthy human subjects. Carbohydr Polym 21(2):189-194. https://doi.org/10.1016/0144-8617(93) 90017-X

76. Ferguson JJ, Stojanovski E, MacDonald-Wicks L, Garg ML (2020) High molecular weight oat $\beta$-glucan enhances lipid-lowering effects of phytosterols. A randomised controlled trial. Clin Nutr 39(1):80-89. https://doi.org/10.1016/j.clnu.2019.02.007

77. Geliebter A, Astbury NM, Aviram-Friedman R, Yahav E, Hashim S (2014) Skipping breakfast leads to weight loss but also elevated cholesterol compared with consuming daily breakfasts of oat porridge or frosted cornflakes in overweight individuals: a randomised controlled trial. J Nutr Sci. https://doi.org/10.1017/ jns.2014.51

78. Gerhardt AL, Gallo NB (1998) Full-fat rice bran and oat bran similarly reduce hypercholesterolemia in humans. J Nutr 128(5):865-869. https://doi.org/10.1093/jn/128.5.865

79. Guevara-Cruz M, Tovar AR, Aguilar-Salinas C, Medina-Vera I, Gil-Zenteno L, Hernández-Viveros I et al (2012) A dietary pattern including nopal, chia seed, soy protein, and oat reduces serum triglycerides and glucose intolerance in patients with metabolic syndrome. J Nutr 142(1):64-69. https://doi.org/10.3945/ jn.111.147447

80. Gulati S, Misra A, Pandey RM (2017) Effects of $3 \mathrm{~g}$ of soluble fiber from oats on lipid levels of Asian Indians-a randomized controlled, parallel arm study. Lipids Health Dis. https://doi.org/ 10.1186/s12944-017-0460-3

81. He J, Streiffer RH, Muntner P, Krousel-Wood MA, Whelton PK (2004) Effect of dietary fiber intake on blood pressure: a randomized, double-blind, placebo-controlled trial. J Hypertens 22(1):73-80. https://doi.org/10.1097/00004872-20040 1000-00015

82. Hegsted M, Windhauser MM, Morris SK, Lester SB (1993) Stabilized rice bran and oat bran lower cholesterol in humans. Nutr Res 13(4):387-398. https://doi.org/10.1016/S0271-5317(05) 80703-1

83. Ibrugger S, Kristensen M, Poulsen MW, Mikkelsen MS, Ejsing J, Jespersen BM, Dragsted LO, Engelsen SB, Bugel S (2013) Extracted oat and barley beta-glucans do not affect cholesterol metabolism in young healthy adults. J Nutr 143(10):1579-1585. https://doi.org/10.3945/jn.112.173054
84. Johansson-Persson A, Ulmius M, Cloetens L, Karhu T, Herzig KH, Önning G (2014) A high intake of dietary fiber influences C-reactive protein and fibrinogen, but not glucose and lipid metabolism, in mildly hypercholesterolemic subjects. Eur J Nutr 53(1):39-48. https://doi.org/10.1007/s00394-013-0496-8

85. Kabir M, Oppert JM, Vidal H, Bruzzo F, Fiquet C, Wursch P, Slama G, Rizkalla SW (2002) Four-week low-glycemic index breakfast with a modest amount of soluble fibers in type 2 diabetic men. Metab Clin Exp 51(7):819-826. https://doi.org/10. 1053/meta.2002.33345

86. Karmally W, Montez MG, Palmas W, Martinez W, Branstetter A, Ramakrishnan R, Holleran SF et al (2005) Cholesterol-lowering benefits of oat-containing cereal in hispanic Americans. J Am Diet Assoc 105(6):967-970. https://doi.org/10.1016/j.jada.2005. 03.006

87. Kashtan H, Stern HS, Jenkins DJ, Jenkins AL, Hay K, Marcon N, Minkin S, Bruce WR (1992) Wheat-bran and oat-bran supplements' effects on blood lipids and lipoproteins. Am J Clin Nutr 55(5):976-980. https://doi.org/10.1093/ajen/55.5.976

88. Keenan JM, Wenz JB, Myers S, Ripsin C, Huang Z (1991) Randomized, controlled, crossover trial of oat bran in hypercholesterolemic subjects. J Fam Pract 33(6):600-608

89. Keenan JM, Pins JJ, Frazel C, Moran A, Turnquist L (2002) Oat ingestion reduces systolic and diastolic blood pressure in patients with mild or borderline hypertension: a pilot trial. J Fam Pract 51(4):369

90. Kerckhoffs DAJM, Hornstra G, Mensink RP (2003) Cholesterollowering effect of $\beta$-glucan from oat bran in mildly hypercholesterolemic subjects may decrease when $\beta$-glucan is incorporated into bread and cookies. Am J Clin Nutr 78(2):221-227. https:// doi.org/10.1093/ajen/78.2.221

91. Kirby RW, Anderson JW, Sieling B (1981) Oat-bran intake selectively lowers serum low-density lipoprotein cholesterol concentrations of hypercholesterolemic men. Am J Clin Nutr 34(5):824-829. https://doi.org/10.1093/ajcn/34.5.824

92. Kristensen M, Bügel S (2011) A diet rich in oat bran improves blood lipids and hemostatic factors, and reduces apparent energy digestibility in young healthy volunteers. Eur J Clin Nutr 65(9):1053-1058. https://doi.org/10.1038/ejen.2011.102

93. Laaksonen DE, Toppinen LK, Juntunen KS, Autio K, Liukkonen KH, Poutanen KS, Niskanen L, Mykkänen HM (2005) Dietary carbohydrate modification enhances insulin secretion in persons with the metabolic syndrome. Am J Clin Nutr 82(6):1218-1227. https://doi.org/10.1093/ajen/82.6.1218

94. Leadbetter J, Ball MJ, Mann JI (1991) Effects of increasing quantities of oat bran in hypercholesterolemic people. Am J Clin Nutr 54(5):841-845. https://doi.org/10.1093/ajcn/54.5.841

95. Liao MY, Shen YC, Chiu HF, Ten SM, Lu YY, Han YC, Venkatakrishnan K, Yang SF, Wang CK (2019) Down-regulation of partial substitution for staple food by oat noodles on blood lipid levels: a randomized, double-blind, clinical trial. J Food Drug Anal 27(1):93-100. https://doi.org/10.1016/j.jfda.2018.04.001

96. Liatis S, Tsapogas P, Chala E, Dimosthenopoulos C, Kyriakopoulos K, Kapantais E, Katsilambros N (2009) The consumption of bread enriched with betaglucan reduces LDL-cholesterol and improves insulin resistance in patients with type 2 diabetes. Diabetes Metab 35(2):115-120. https://doi.org/10.1016/j.diabet. 2008.09.004

97. Liu S, Yang N, Hou ZH, Yao Y, Lu L, Zhou XR, Ren GX (2011) Antioxidant effects of oats avenanthramides on human serum. Agric Sci China 10(8):1301-1305. https://doi.org/10.1016/ S1671-2927(11)60122-3

98. Lovegrove JA, Clohessy A, Milon H, Williams CM (2000) Modest doses of $\beta$-glucan do not reduce concentrations of potentially atherogenic lipoproteins. Am J Clin Nutr 72(1):49-55. https:// doi.org/10.1093/ajcn/72.1.49 
99. Maki KC, Shinnick F, Seeley MA, Veith PE, Quinn LC, Hallissey PJ, Temer A, Davidson MH (2003) Food products containing free tall oil-based phytosterols and oat beta-glucan lower serum total and LDL cholesterol in hypercholesterolemic adults (2003). J Nutr. 133(3):808-813. https://doi.org/10.1093/jn/133.3.808

100. Maki KC, Galant R, Samuel P, Tesser J, Witchger MS, RibayaMercado JD, Blumberg JB, Geohas J (2007) Effects of consuming foods containing oat $\beta$-glucan on blood pressure, carbohydrate metabolism and biomarkers of oxidative stress in men and women with elevated blood pressure. Eur J Clin Nutr 61(6):786795. https://doi.org/10.1038/sj.ejen.1602562

101. Maki KC, Beiseigel JM, Jonnalagadda SS, Gugger CK, Reeves MS, Farmer MV, Kaden VN, Rains TM (2010) Whole-grain ready-to-eat oat cereal, as part of a dietary program for weight loss, reduces low-density lipoprotein cholesterol in adults with overweight and obesity more than a dietary program including low-fiber control foods. J Am Diet Assoc 110(2):205-214. https://doi.org/10.1016/j.jada.2009.10.037

102. Mårtensson $\mathrm{O}$, Biörklund $\mathrm{M}$, Lambo AM, Dueñas-Chasco M, Irastorza A, Holst O et al (2005) Fermented, ropy, oat-based products reduce cholesterol levels and stimulate the bifidobacteria flora in humans. Nutr Res 25(5):429-442. https://doi.org/10. 1016/j.nutres.2005.03.004

103. Missimer A, Dimarco DM, Andersen CJ, Murillo AG, VergaraJimenez M, Fernandez ML (2017) Consuming two eggs per day, as compared to an oatmeal breakfast, increases plasma ghrelin while maintaining the LDL/HDL ratio. Nutrient. https://doi.org/ 10.3390/nu9020089

104. Momenizadeh A, Heidari R, Sadeghi M, Tabesh F, Ekramzadeh M, Haghighatian Z et al (2014) Effects of oat and wheat bread consumption on lipid profile, blood sugar, and endothelial function in hypercholesterolemic patients: a randomized controlled clinical trial. ARYA Atheroscler 10(5):259

105. Noakes M, Clifton PM, Nestel PJ, Le Leu R, McIntosh G (1996) Effect of high-amylose starch and oat bran on metabolic variables and bowel function in subjects with hypertriglyceridemia. Am J Clin Nutr 64(6):944-951. https://doi.org/10.1093/ajen/64.6.944

106. Önning G, Wallmark A, Persson M, Åkesson B, Elmståhl S, Öste R (1999) Consumption of oat milk for 5 weeks lowers serum cholesterol and LDL cholesterol in free-living men with moderate hypercholesterolemia. Ann Nutr Metab 43(5):301-309. https:// doi.org/10.1159/000012798

107. Önning G, Åkesson B, Öste R, Lundquist I (1998) Effects of consumption of oat milk, soya milk, or cow's milk on plasma lipids and antioxidative capacity in healthy subjects. Ann Nutr Metab 42(4):211-220. https://doi.org/10.1159/000012736

108. Pins JJ, Geleva D, Keenan JM, Frazel C, O’Connor PJ, Cherney LM (2002) Do whole-grain oat cereals reduce the need for antihypertensive medications and improve blood pressure control? J Fam Pract 51(4):353-359

109. Poulter N, Chang CL, Cuff A, Poulter C, Sever P, Thom S (1994) Lipid profiles after the daily consumption of an oat-based cereal: a controlled crossover trial. Am J Clin Nutr 59(1):66-69. https:// doi.org/10.1093/ajen/59.1.66

110. Reyna-Villasmil N, Bermúdez-Pirela V, Mengual-Moreno E, Arias N, Cano-Ponce C, Leal-Gonzalez E et al (2007) Oatderived $\beta$-glucan significantly improves HDLC and diminishes LDLC and non-HDL cholesterol in overweight individuals with mild hypercholesterolemia. Am J Ther 14(2):203-212. https:// doi.org/10.1097/01.pap.0000249917.96509.e7

111. Robitaille J, Fontaine-Bisson B, Couture P, Tchernof A, Vohl MC (2005) Effect of an oat bran-rich supplement on the metabolic profile of overweight premenopausal women. Ann Nutr Metab 49(3):141-148. https://doi.org/10.1159/000086149

112. Romero AL, Romero JE, Galaviz S, Fernandez ML (1998) Cookies enriched with psyllium or oat bran lower plasma LDL cholesterol in normal and hypercholesterolemic men from Northern Mexico. J Am Coll Nutr 17(6):601-608. https://doi.org/10. 1080/07315724.1998.10718809

113. Saltzman E, Das SK, Lichtenstein AH, Dallal GE, Corrales A, Schaefer EJ, Greenberg AS, Roberts SB (2001) An oat-containing hypocaloric diet reduces systolic blood pressure and improves lipid profile beyond effects of weight loss in men and women. J Nutr. 131(5):1465-1470. https://doi.org/10.1093/jn/ 131.5.1465

114. Schweinlin A, Ulbrich S, Stau $\beta$ S, Teutsch M, Walle H, Basrai M, Bischoff SC (2018) Comparison of a commercially available, formula-based nutritional therapy enriched with oats fiber with a non-formula isocaloric therapy to treat non-alcoholic fatty liver disease (NAFLD)-a randomized, controlled intervention trial. Z Gastroenterol 56(10):1247-1256. https://doi.org/10. 1055/a-0668-2891

115. Tabesh F, Sanei H, Jahangiri M, Momenizadeh A, Tabesh E, Pourmohammadi K, Sadeghi M (2014) The effects of beta-glucan rich oat bread on serum nitric oxide and vascular endothelial function in patients with hypercholesterolemia. Biomed Res Int. https://doi.org/10.1155/2014/481904

116. Theuwissen E, Plat J, Mensink RP (2009) Consumption of oat $\beta$-glucan with or without plant stanols did not influence inflammatory markers in hypercholesterolemic subjects. Mol Nutr Food Res 53(3):370-376. https://doi.org/10.1002/mnfr.200800132

117. Thongoun P, Pavadhgul P, Bumrungpert A, Satitvipawee P, Harjani Y, Kurilich A (2013) Effect of oat consumption on lipid profiles in hypercholesterolemic adults. J Med Assoc Thai 96(Suppl 5):S25-32

118. Trinidad TP, Loyola AS, Mallillin AC, Valdez DH, Askali FC, Castillo JC et al (2004) The cholesterol-lowering effect of coconut flakes in humans with moderately raised serum cholesterol. J Med Food 7(2):136-140. https://doi.org/10.1089/1096620041 224148

119. Uusitupa MIJ, Miettinen TA, Sarkkinen ES, Ruuskanen E, Kervinen K, Kesäniemi YA (1997) Lathosterol and other noncholesterol sterols during treatment of hypercholesterolaemia with beta-glucan-rich oat bran. Eur J Clin Nutr 51(9):607-611. https://doi.org/10.1038/sj.ejen.1600453

120. Uusitupa MIJ, Ruuskanen E, Makinen E, Laitinen J, Toskala E, Kervinen K, Kesaniemi YA (1992) A controlled study on the effect of beta-glucan-rich oat bran on serum lipids in hypercholesterolemic subjects: relation to apolipoprotein E phenotype. J Am Coll Nutr 11(6):651-659. https://doi.org/10.1080/07315724. 1992.10718264

121. Vanhorn L, Moagstahlberg A, Liu K, Ballew C, Ruth K, Hughes $\mathrm{R}$, Stamler J (1991) Effects on serum-lipids of adding instant oats to usual American diets. Am J Public Health 81(2):183-188. https://doi.org/10.2105/ajph.81.2.183

122. Vuksan V, Jenkins AL, Brissette C, Choleva L, Jovanovski E, Gibbs AL, Bazinet RP, Au-Yeung F, Zurbau A, Ho HVT, Duvnjak L, Sievenpiper JL, Josse RG, Hanna A (2017) Salba-chia (Salvia hispanica L.) in the treatment of overweight and obese patients with type 2 diabetes: a double-blind randomized controlled trial. Nutr Metab Cardiovasc Dis 27(2):138-146. https:// doi.org/10.1016/j.numecd.2016.11.124

123. Wolever TM, Tosh SM, Gibbs AL, Brand-Miller J, Duncan AM, Hart V et al (2010) Physicochemical properties of oat betaglucan influence its ability to reduce serum LDL cholesterol in humans: a randomized clinical trial. Am J Clin Nutr 92(4):723732. https://doi.org/10.3945/ajen.2010.29174

124. Zhang J, Li L, Song P, Wang C, Man Q, Meng L, Cai J, Kurilich A (2012) Randomized controlled trial of oatmeal consumption versus noodle consumption on blood lipids of urban Chinese adults with hypercholesterolemia. Nutr J. https://doi.org/10.1186/ 1475-2891-11-54 


\section{Authors and Affiliations}

\section{Erand Llanaj ${ }^{1,2} \cdot$ Gordana M. Dejanovic $^{3} \cdot$ Ezra Valido $^{4} \cdot$ Arjola Bano $^{9,14} \cdot$ Magda Gamba9,13 $^{\text {Lum Kastrati }}{ }^{10}$. Beatrice Minder ${ }^{11}$. Stevan Stojic ${ }^{4}$. Trudy Voortman ${ }^{5,6} \cdot$ Pedro Marques-Vidal $^{7,8}$. Jivko Stoyanov ${ }^{4,9}$. Brandon Metzger $^{12}$ - Marija Glisic ${ }^{4,9} \cdot$ Hua Kern $^{12} \cdot$ Taulant Muka $^{9}$}

Erand Llanaj

erand.llanaj@med.unideb.hu

Gordana M. Dejanovic

dr.dejanovic@yahoo.com

1 Department of Public Health and Epidemiology, Faculty of Medicine, University of Debrecen, Debrecen, Hungary

2 Present Address: MTA-DE Public Health Research Group, Hungarian Academy of Sciences and University of Debrecen, Debrecen, Hungary

3 Department of Ophthalmology, Faculty of Medicine, University of Novi Sad, Novi Sad, Serbia

4 Swiss Paraplegic Research, Nottwil, Switzerland

5 Department of Epidemiology, Erasmus MC University Medical Centre Rotterdam, Rotterdam, The Netherlands

6 Division of Human Nutrition and Health, Wageningen University, Wageningen, The Netherlands
7 Department of Medicine, Internal Medicine, Lausanne University Hospital, Lausanne, Switzerland

8 University of Lausanne, Lausanne, Switzerland

9 Institute of Social and Preventive Medicine (ISPM), University of Bern, Bern, Switzerland

10 Faculty of Medicine, University of Prishtina "Hasan Prishtina", Prishtina, Kosovo

11 Public Health and Primary Care Library, University Library of Bern, University of Bern, Bern, Switzerland

12 Standard Process Nutrition Innovation Centre, Kannapolis, USA

13 Graduate School for Health Sciences, University of Bern, Bern, Switzerland

14 Department of Cardiology, University Hospital of Bern, University of Bern, Bern, Switzerland 